\title{
IL-1ß Primed Mesenchymal Stromal Cells Alleviate Chronic Prostatitis/chronic Pelvic Pain Syndrome Through Systemic Immunity
}

Hanchao Liu

Sun Yat-sen University First Affiliated Hospital

\section{Xinning Zhu}

zhong shan da xue fu shu di liu yi yuan: Sun Yat-sen University Sixth Affiliated Hospital

Ani Chi

Sun Yat-sen University First Affiliated Hospital

Jian Dai

Sun Yat-sen University First Affiliated Hospital

\section{Zhenqing Wang}

Sun Yat-sen University First Affiliated Hospital

\section{Chunhua Deng}

Sun Yat-sen University First Affiliated Hospital

Min Zhang ( $\nabla$ zhangm287@mail.sysu.edu.cn )

Sun Yat-sen University First Affiliated Hospital

\section{Research}

Keywords: IL-1 $\beta$-primed MSCs, systemic immunity, immunoregulation, CP/CPPS, pain

Posted Date: July 20th, 2021

DOl: https://doi.org/10.21203/rs.3.rs-720549/v1

License: (9) This work is licensed under a Creative Commons Attribution 4.0 International License. Read Full License 


\section{Abstract}

Background: Chronic prostatitis/chronic pelvic pain syndrome (CP/CPPS) seriously affects patient health. Despite the elusiveness of innate therapeutic effects, mesenchymal stromal cells (MSCs) hold great promise for inflammation-related diseases. Recent evidence indicates that disease-specific inflammatory cytokines could enhance the therapeutic effects of MSCs.

Methods: By establishing a CP/CPPS mouse model and pretreating MSCs with the cytokine interleukin-1 $\beta$

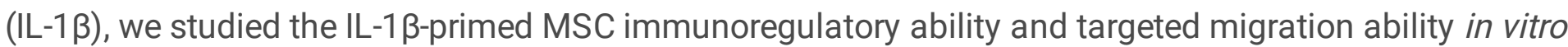
and in CP/CPPS mice.

Results: IL-1 $\beta$ levels significantly increased in the prostate tissue and serum of experimental autoimmune prostatitis (EAP) mice. Pretreatment with IL-1 $\beta$ enhanced the immunomodulatory potential and targeted migration of MSCs in vitro. Furthermore, intravenous infusion of IL-1 $\beta$-primed MSCs dampened inflammation in prostate tissues and alleviated hyperalgesia in EAP mice. The infused MSCs inhibited monocyte infiltration and promoted regulatory $T$ lymphocyte formation in prostate tissue, thus remodeling the local environment. Surprisingly, IL-1ß-primed MSCs exhibited improved accumulation in the spleen but not in prostate tissue. Accordingly, infused MSCs reshaped systemic immunity by reducing the proportion of Ly6 $\mathrm{C}^{\text {high }} \mathrm{CD} 11 \mathrm{~b}^{+}$monocytes and boosting the proportion of $\mathrm{CD} 4^{+} \mathrm{Foxp} 3^{+}$regulatory $\mathrm{T}$ lymphocytes in the spleen and lung. Inflammatory chemokine (C-C motif) ligand 2 (CCL2) decreased through the downregulation of the NF-KB and JNK/MAPK pathways by inflammatory resolution via MSCs infusion to alleviate pain.

Conclusion: In summary, IL-1 $\beta$ primed MSCs restored systemic immunologic homeostasis to alleviate $\mathrm{CP} / \mathrm{CPPS}$ by modulating systemic immunity. These findings provide a novel strategy to boost the therapeutic effects of MSC-based therapy for CP/CPPS and reveal the essential role of systematic immunity in the treatment of CP/CPPS with MSC infusion.

\section{Introduction}

Chronic prostatitis/chronic pelvic pain syndrome (CP/CPPS) is a common disorder with chronic pelvic pain, prostatic inflammation, lower urinary tract symptoms, and sexual dysfunction [1, 2]. Epidemiologic studies have shown that CP/CPPS accounts for approximately $90 \%-95 \%$ of all prostatitis diagnoses and affects approximately $8 \%-11.5 \%$ of men younger than 50 years $[3,4]$, comparable to ischemic heart disease and diabetes mellitus. Unfortunately, chronic urological pain is closely associated with psychosocial dysfunction, including depression, anxiety, and catastrophizing, thus severely impacting patient quality of life [1]. Like other chronic pain disorders, the etiology and efficient treatment of $\mathrm{CP} / \mathrm{CPPS}$ is still enigmatic $[1,3]$. Recent evidence suggests that immunological disorders are pivotal in the pathophysiological progression of CP/CPPS and other chronic pain syndromes [4-7]. For example, Mailhot B et al. reported that interleukin-1 $\beta$ (IL-1 $\beta$ ) drives chronic pain in multiple sclerosis, arthritis, and osteoarthritis [8]. Clinical trials have demonstrated that anti-inflammatory agents, including 
cyclooxygenase and corticosteroids, could lead to symptomatic improvement in CP/CPPS patients [9, 10]. However, due to the nonspecific suppression of immunity as a whole, immunosuppressive agents inevitably aggravate immune disorders when administered in the long-term. Possessing the capacity to rebalance dysregulated immunity, mesenchymal stromal cells (MSCs) have been intensively investigated in various preclinical studies and clinical trials for their translational potential in combating chronic immunological disorders [11]. Therefore, it is imperative to elucidate the therapeutic effects of MSCbased therapy for CP/CPPS.

Although encouraging, the innate therapeutic outcomes of MSC-based therapies are limited and variable $[12,13]$. Therefore, it is one of the major challenges to explore priming strategies specifically tailored to optimize MSC potency for specific disease indications [14]. Stem cells possess the ability to sense environmental pressures and actively alter their epigenetic landscapes and corresponding functions to rapidly adapt to secondary assaults [15]. Notably, MSCs could also trigger a memory effect after a transient stimulus [14]. For example, Li CX et al. demonstrated that mechanical stimulus in the culture expansion period elicited the myofibroblast memory of MSCs and was sufficient to exert biased fibrogenic differentiation after transplantation in vivo [16]. That is, a specific stimulus in vitro could poise MSCs to remember the stress and avoid the lag time for in vivo activation after infusion in specific clinical settings. It is generally accepted that pretreatment with inflammatory cytokines could enhance the immunomodulatory functions of MSCs and their potential therapeutic efficiencies by imitating the in vivo inflammatory context $[11,17]$. For example, preconditioning MSCs with inflammatory cytokines was shown to increase the secretion of immunomodulatory molecules, including TNF-stimulated gene 6 protein (TSG-6), Prostaglandin E2 (PGE-2) and galectins [17]. Therefore, it is pivotal to explore appropriate priming strategies to facilitate MSC-based therapies for CP/CPPS.

The mechanisms of MSC-mediated immunomodulation are multifaceted in a disease-dependent manner $[11,17-19]$. In general, MSCs can orchestrate local and systemic immunity in the context of an inflammatory environment [11,17-19]. It is believed to be essential for the therapeutic efficiencies of MSC infusion that the abilities of exogenously delivered MSCs home to the lesion tissue to remodel the local microenvironment [20-22]. However, other researchers argue that the therapeutic functions of systemically administered MSCs rely on their abilities to restore systemic immunological homeostasis [23-25]. For example, Murphy $\mathrm{N}$ et al. revealed that TNF- $\mathrm{a} / \mathrm{IL}-1 \beta$-primed MSCs could sustain corneal allograft survival via the induction of regulatory $T$ lymphocyte expansion in the lung [25]. Huang $Y$ et al. found that MSCs could ameliorate spontaneous infection of acute ischemic stroke by preserving spleen B cells via mitochondrial transfer [26]. Moreover, Yi S et al. demonstrated that infused MSCs hardly migrate into prostate tissues in chronic bacterial prostatitis rat models due to the blood-prostate barrier [27].

Therefore, further investigation is needed to clarify the influence of MSC infusion on systematic and local immunity in CP/CPPS.

In this study, through the establishment of a CP/CPPS mouse model, we found that the expression of IL$1 \beta$ was widely increased in the spleen, bloodstream and prostate. After priming MSCs with IL-1 $\beta$, it was discovered that the NF-KB pathway of MSCs was activated. The TSG-6 and COX-2 pathways were more 
highly expressed in IL-1 $\beta$-primed MSCs, and the immunomodulatory ability was enhanced. The expression of chemokine C-X-C motif receptor 4 (CXCR4) increased. We further proved that the accumulation of IL-1 $\beta$-primed MSCs in the spleen increased. The MSC immunomodulatory ability and targeted migration to the spleen were enhanced after IL-1 $\beta$ priming. After MSC infusion, the migration and differentiation of mononuclear cells/macrophages in the bloodstream, spleen, lung and prostate decreased. The number of $\mathrm{CD}^{+}{ }^{+} \mathrm{Foxp}^{+}$Treg cells in the bloodstream, spleen, lung and prostate increased. Anti-inflammatory macrophages in the prostate were increased, and inflammation in the prostate was alleviated. The pain-related inflammatory cytokine chemokine (C-C motif) ligand 2 (CCL2) was reduced in the prostate through MSC immunoregulation in systemic immunity.

\section{Method}

\section{Mice and cell resources}

Human umbilical cord samples were collected from six full-term newborns. All samples were collected with patient consent and signed informed consent. This study was approved by the Ethics Committee of the First Affiliated Hospital of Sun Yat-sen University (approval number: SYSU-IACUC-2018-168-1).

Male NOD/ShiLtJ mice (6-8 weeks old) were purchased from Jiangsu Gempharmatech. All mice were kept under controlled temperature $\left(24^{\circ} \mathrm{C} \pm 1^{\circ} \mathrm{C}\right)$ and relative humidity $(50 \%-60 \%)$. The light period was 12 hours, and the dark period was 12 hours. All mice were allowed free access to food and water. All surgical procedures and postoperative nursing methods were approved by the Animal Care and Use Committee of Sun Yat-sen University (approval number: SYSU-IACUC-2021-000164). On a specified date, the mice were euthanized by inhaling excessive amounts of isoflurane, according to the American Veterinary Medical Association (AVMA) Guidelines for the Euthanasia of Animals: 2013 Edition.

\section{Isolation, culture, and pretreatment of human umbilical cord-derived MSCs}

As previously described, MSCs were isolated from the umbilical cord of newborns [28]. In short, the blood vessels were carefully removed from the umbilical cord, and the remaining Wharton's jelly was cut up and digested with $1 \mathrm{mg} / \mathrm{mL}$ collagenase II (Micropore) in Hank's balanced salt solution (HBSS, HyClone) for 30 minutes at $37^{\circ} \mathrm{C}$. The isolated cells were filtered through a cell filter with a mesh diameter of $70 \mu \mathrm{m}$ to obtain a cell suspension.

The cells were washed twice with HBSS and cultured in DMEM/F12 (Gibco) supplemented with 10\% fetal bovine serum (FBS, HyClone), 1\% nonessential amino acids (Gibco), 2 mM GlutaMAX (Gibco) and 100 $\mathrm{IU} / \mathrm{mL}$ penicillin/streptomycin (Gibco) in a humidified $5 \% \mathrm{CO}_{2}$ water-jacketed incubator (Thermo Scientific). The culture medium was changed every 3 days. Cells were passaged every $2-3$ days using $0.125 \%$ trypsin (Gibco) at a split ratio of 1:3. MSCs of the 4th passage were cocultured with $10 \mathrm{ng} / \mathrm{ml} \mathrm{IL-}$ $1 \beta$ (PeproTech) for 48 hours.

The lentivirus carrying green fluorescent protein (GFP) was purchased from Shanghai Genechem Co., Ltd. Transfection was carried out according to the instructions. After successful transfection, flow cytometry 
was used to screen GFP + cells for further expansion.

\section{Animal model}

The construction of a non-obesity diabetes-experimental autoimmune prostatitis (NOD-EAP) mouse model was performed according to a previously published article [29, 30]. The EAP mouse model was established by mixing the male reproductive accessory gland (MAG) extract of male Wistar rats with the same volume of complete Freund's adjuvant (CFA, Sigma). After repeated suction and mixing, the NOD mice were injected with a mixture of MAG extract and CFA in four different parts, namely, the neck (0.025 $\mathrm{ml})$, tail $(0.050 \mathrm{ml})$ and bilateral shoulders $(0.050 \mathrm{ml})$, on days 0 and 15 . At 30 days, MSCs and IL-1 $\beta$ primed MSCs were injected into EAP mice through the tail vein. On the indicated days, the spleen, blood, and prostate were collected for flow cytometry analysis, cytokine measurements, and histological analysis.

\section{Hyperalgesia behavior testing}

The test was performed 30 days after the first injection and 15 days after the treatment. According to published articles, von Frey filaments were used to test hyperalgesia in the abdomen and the plantar area of the hind paw $[31,32]$. In short, five different fibers were used to test the frequency of the withdrawal response by von Frey filaments applied to the pelvis and lower abdomen with forces of $0.04,0.16,0.4,1.0$ and $4.0 \mathrm{~g}$. There are four types of behaviors that are considered to be a positive response to filament stimulation: sharp retraction of the abdomen, immediate licking, scratching of the filament stimulation area or jumping. The frequency of response was calculated as the percentage of positive responses, and the data are reported as the average percentage of the response frequency. The $50 \%$ threshold was evaluated using an up and down method [33].

\section{Coculture of macrophages and MSCs}

The bone marrow cells surgically obtained from the femur or tibia were separated by density gradient centrifugation. The cells were grown and maintained with DMEM/F12 (HyClone) containing 10\% FBS and $20 \%$ L929 conditioned medium in low adhesion plates. After 7 days of culturing, the cells were separated with TrypLETM Express (Gibco) and seeded at a density of 5×105 cells/well. Then, $1 \mu \mathrm{g} / \mathrm{mL}$ lipopolysaccharide (LPS, Sigma) was added to activate macrophages. Macrophages and saline/MSCs/IL-1ß-primed MSCs were cocultured at a ratio of 5:1. After 72 hours of cocultivation, the cells were collected and analyzed by flow cytometry.

\section{Coculture of $\mathrm{CD}^{+}$cells and MSCs}

T lymphocytes were obtained from the spleen using the BioLegend Natural CD4 + T Cell Purification Kit (BioLegend) and then seeded on anti-CD3-coated plates at a density of $5 \times 105$ cells/well. CD $4+T$ cells and saline/MSCs/IL-1 $\beta$-primed MSCs were cocultured at a ratio of 5:1. Treg cell differentiation was induced with RPMI 1640 containing 10\% FBS, 3 mg/mL anti-CD28 (BioLegend), 50 ng/mL IL-2 
(Novoprotein) and $5 \mathrm{ng} / \mathrm{mL}$ TGF- $\beta$ (Novoprotein). After 72 hours of cocultivation, CD $4+$ FOXP3 + Treg cells were collected and analyzed by flow cytometry.

\section{$\mathrm{Ca}^{2+}$ imaging in DRGs}

According to the previously published literature [34, 35], dorsal root ganglia (DRGs) (T13-L2) were isolated from male mice aged 4 to 6 weeks and incubated with collagenase (Sigma). They were then incubated at $37^{\circ} \mathrm{C}$ for 45 minutes, digested with $0.05 \%$ trypsin-EDTA (Gibco), resuspended in complete medium (DMEM/F12), and cultured on coverslips for 3 days. A normal physiological salt wash (containing 140 $\mathrm{mM} \mathrm{NaCl}, 5 \mathrm{mM} \mathrm{KCl}, 1 \mathrm{mM} \mathrm{MgCl} 2,2.5 \mathrm{mM} \mathrm{CaCl}_{2}, 10 \mathrm{mM}$ HEPES and $10 \mathrm{mM}$ glucose) was used for washing 3 times, and the $\mathrm{pH}$ was adjusted to 7.4. The cells were incubated with $5 \mu \mathrm{M}$ fluo 3-AM (Molecular Probes) for 60 minutes at room temperature. The fluorescence signal was recorded by a laser scanning imaging system (IX83 research inverted microscope, Japan). Fluo 3 is excited at $488 \mathrm{~nm}$ and analyzed at $530 \mathrm{~nm}$. After equilibrating for 3-5 minutes, the cells were treated with CCL2 and capsaicin to increase $\mathrm{Ca}^{2+}$ influx. The $\mathrm{Ca}^{2+}$ signal was captured in a $4 \mathrm{~s}$ interval.

\section{Transwell migration assay}

An 8- $\mu \mathrm{m}$ pore membrane filter (Millipore) was used to evaluate the targeted migration ability of MSCs. Serum-free starved MSCs and IL-1 $\beta$-primed MSCs were inoculated in the upper chamber $\left(1 \times 10^{5}\right.$ cells per well), while the lower chamber was filled with $500 \mu \mathrm{L}$ of DMEM/F12, which contained $50 \mathrm{ng} / \mathrm{mL}$ mouse Chemokine (C-X-Cmotif) ligand 12 (CXCL12, PeproTech). After incubating in $5 \% \mathrm{CO}_{2}$ at $37^{\circ} \mathrm{C}$ for 12 hours, the upper chamber of the filter was removed. After fixing with $4 \%$ paraformaldehyde (PFA), the cells that migrated to the lower chambers were stained with $0.1 \%$ crystal violet and then counted by microscopy.

\section{Flow cytometry}

The obtained tissues were cut into small pieces and shaken with Liberase TL (100 U/mL; Roche) with DNase I (100 U/mL; Sigma) in a $37^{\circ} \mathrm{C}$ water bath for 20 minutes. Subsequently, the cell suspensions were passed through a $70-\mu \mathrm{m}$ cell strainer to produce single cells. The collected peripheral blood samples were subjected to red blood cell lysis (BioLegend) and then washed twice with PBS. Single-cell suspensions, tissues and blood samples were incubated with the appropriate antibodies (Supplementary Table S1) for 15 minutes in the dark. The cells were washed twice, resuspended in PBS and analyzed by MoFlo Astrios EQ (Beckman Coulter) for at least three independent experiments. The data was analyzed using FlowJo V10.0 (Tree Star). Information on the antibodies is listed in Supplementary Table S1.

\section{Quantitative real-time PCR (RT-qPCR)}

Total RNA was extracted and purified by NucleoZol reagent (Macherey-Nagel), and cDNA was obtained by a cDNA library kit (Takara). qRT-PCR was conducted on a Bio-Rad CFX96TM detection system (Roche) with SYBR PCR Master Mix (Roche). $\beta$-Actin was used for standardization. The primers used are listed in Supplementary Table S2. 


\section{Tissue preparations and histological analysis}

Tissue was embedded in a tissue-Tek optimum cutting temperature (OCT) complex and frozen in a cryostat (Leica CM1900, Germany). Sections of 5- $\mu \mathrm{m}$ thickness were then placed on glass slides (BioOptical). Slices were prepared and sealed with $0.05 \%$ thiobarbital sodium-Tween containing $0.5 \%$ FBS for 30 minutes, incubated overnight with the primary antibody or an IgG control antibody at $4{ }^{\circ} \mathrm{C}$, and incubated for 60 minutes with the secondary antibody at room temperature. The slices were re-stained with 4',6-diamidino-2-phenylindole (DAPI) for 3 minutes at room temperature. Immunofluorescence (IF) signals were visualized and recorded using a laser scanning confocal microscope (LSM780, Zeiss, Germany). For hematoxylin-eosin (HE) staining, the tissue was fixed overnight in 4\% PFA (Sigma), continuously dehydrated and embedded in paraffin. Then, slices with a thickness of $5 \mu \mathrm{m}$ were placed on glass slides (Bio-Optical). The cells were stained with an HE staining kit (Servicebio). All the primary and secondary antibodies are listed in Supplementary Table S2.

\section{Western blot analysis}

Cultured cells or tissues were homogenized with RIPA lysis buffer (Millipore) containing protease inhibitors for over 30 minutes. Nuclear protein lysates were generated using a nuclear protein extract kit (Servicebio) following the manufacturer's instructions. The homogenates were centrifuged at 15,000 $\times \mathrm{g}$ at $4^{\circ} \mathrm{C}$ for 10 minutes and then the protein concentration was detected by a BCA protein analysis kit (Sigma). Approximately 20-40 $\mu \mathrm{g}$ of total protein solution was loaded onto SDS-polyacrylamide gels and transferred onto 0.22- $\mu \mathrm{m}$ polyvinylidene fluoride (PVDF) membranes (Millipore). The membranes were blocked with $5 \%$ bovine serum albumin for 30 minutes at room temperature and then probed with the indicated primary antibody at $4^{\circ} \mathrm{C}$ overnight, followed by incubation with the horseradish peroxidaseconjugated secondary antibody at room temperature for 1 hour. A chemiluminescence kit (Millipore) was used to detect the target bands. Information about the antibodies used is provided in Supplementary Table S1.

\section{Cytokine measurements}

Tissue was homogenized with TissueLyser II (QIAGEN) and 5-mm steel balls (QIAGEN) in tissue protein extraction reagent (Thermo Fisher), and the supernatant was obtained after centrifugation. Blood samples were collected, and serum was extracted by centrifugation. According to the manufacturer's instructions, the LEGENDplex ${ }^{\mathrm{TM}}$ mouse inflammatory panel (BioLegend) was used to detect the concentration of 13 cytokines in tissue culture supernatants, serum samples and lysates extracted from RIPA. Vacuum freeze-drying equipment (Songyuan) was used to concentrate the extract to obtain the appropriate concentration. A BCA protein analysis kit (Sigma) was used to determine the concentration of total protein in the lysate extracted by RIPA, and the same amount of total protein was used for subsequent detection. The kit provides capture beads that bind to specific antibodies, making them easily distinguishable by size and fluorescence signal. The biological sample was incubated with the capture beads at room temperature for 2 hours and then a biotin-labeled detection antibody was added for flow cytometry detection. LEGENDplex 8.0 data analysis software was used to calculate the average 
fluorescence intensity corresponding to each cytokine. The cytokine concentration was measured by comparing the fluorescence intensity with a standard value.

\section{Statistics}

Comparisons between groups were performed by t-test or one-way analysis of variance (ANOVA), and Tukey's multiple comparison test was used. Error bars indicate the standard error of the mean. $P<0.05$ was considered statistically significant. All statistical analyses were performed with GraphPad Prism 8.0 software.

\section{Result}

\section{IL-1 $\beta$ is elevated in the spleen, bloodstream and prostate of NOD-EAP mice.}

The etiology, pathogenesis, and optimal treatment of CP/CPPS are poorly understood, and we have adopted the most recognized and applied CP/CPPS animal model (NOD-EAP mouse model) by CP/CPPS researchers [36, 37]. HE staining and pain behavior detection proved that the NOD-EAP mouse model was successfully established. At 30th day after the 1 st immunization, prostate HE staining in the CP/CPPS mice showed a large amount of inflammatory cell infiltration and tissue structure destruction (Fig. 1A). The inflammation score of the model group was significantly increased compared with that of the control group, and the body mass was not significantly different between the two groups (Fig. 1B). The pelvic pain between the control group and the model group were significantly different, indicating that the mice in the model group had significant pelvic pain (Fig. 1C). The mice in the control group showed no significant differences in pelvic pain at 0 and 30 days (Fig. 1C). The behavior detection of paw pain showed no significant differences, which indicates that this pain is pelvic-specific pain (Fig. 1C). The pelvic pain difference between 0 and 30 days was statistically significant in EAP mice (Fig. 1C).

We have mentioned that the immunomodulatory ability and MSC homing efficiency of MSCs can be enhanced by cytokines [38-40]. As an inflammatory cytokine, IL-1 $\beta$ plays a critical role in autoimmune conditions, inflammation and neuropathic pain [41]. IL-1 $\beta$ was widely expressed in the spleen and prostate of CP/CPPS mice by RT-qPCR and Western blotting. The mRNA expression levels of inflammatory factors were significantly different in the spleens (Fig. 1D) and prostates (Fig. 1E) of the model group and the control group (Fig. 1D). Western blotting showed that the expression levels of IL-1 $\beta$ in the spleen (Fig. 1F) and prostate (Fig. 1G) were significantly increased in the model group. Moreover, the Biolegendplex ${ }^{\text {TM }}$ panel showed that serum IL-1 $\beta$ was significantly increased in the model group (Fig. $1 \mathrm{H})$. As a highly expressed inflammatory cytokine in the spleen, bloodstream and prostate of CP/CPPS mice, IL-1 $\beta$ was our ideal pretreatment factor.

IL-1 $\beta$-primed MSCs showed better immune regulation ability and targeted migration ability than MSCs in vitro. 
Recently, researchers have discovered the enhanced immunoregulatory ability and MSC homing efficiency of cytokine-primed MSCs due to the activation of the NF-KB pathway [42, 43]. IL-1 $\beta$ activated the NF-KB pathway of MSCs via phosphorylation of P65, as shown by Western blot analysis (Figure S1A). Flow cytometry analysis showed that IL-1 $\beta$ did not alter the expression patterns of MSC-specific surface markers. The proliferation ability and appearance were not significantly different between the two groups (Figure S1B, C, D). Activation of NF-KB in MSCs after IL-1 $\beta$ priming led to the increased secretion of downstream immunomodulatory proteins and chemokine receptors [44] [45]. IL-1 $\beta$-primed MSCs showed the activation of CXCR4 and COX-2, TSG- 6 and some other genes by RT-qPCR (Fig. 2A). Activation of the CXCL12/CXCR4 axis promoted the MSC secretion of pro-survival and pro-angiogenic cytokines and the targeted engraftment ability of MSCs $[46,47]$. The upregulation of the chemokine receptor CXCR4 proved that its migratory ability in response to CXCL12 was enhanced. Western blotting verified that CXCR4 expression in primed MSCs increased (Fig. 2B). In the Transwell experiment, CXCL12 protein was placed in the lower chamber of the Transwell, and the IL-1 $\beta$-primed MSC-targeted migration ability in response to CXCL12 was enhanced (Fig. 2C). The scratch experiment proved that the migration ability of MSCs after priming was also enhanced (Figure S1E). In vitro, MSCs and mouse bone marrow-derived macrophages were cocultured, and it was found that IL-1 $\beta$-primed MSCs regulated the anti-inflammatory properties of $\mathrm{CD} 45+\mathrm{F} 4 / 80+$ macrophages with increased $\mathrm{CD} 206^{+}$or arginase $1\left(\mathrm{Arg}^{+}\right)$frequency and regulated the proinflammatory properties of $\mathrm{CD} 45+\mathrm{F} 4 / 80+$ macrophages with decreased $\mathrm{CD} 86^{+}$or inducible nitric oxide synthase enzyme (iNOS ${ }^{+}$) frequency (Fig. 2D, E). Gate selection is presented (Figure S2A). To immunoregulate the proportion of Treg cells, MSCs and mouse spleen $\mathrm{CD} 4^{+} \mathrm{T}$ cells were cocultured, and it was found that IL-1 $\beta$-primed MSCs maintained a higher proportion of Treg cells (Fig. 2F); gate selection was presented (Figure S2B). In vitro, we confirmed that the immunoregulatory and target migration abilities were enhanced in IL-1 $\beta$-primed MSCs.

\section{IL-1 $\beta$-primed MSCs targeted migration to the spleen more than MSCs.}

MSC homing and engraftment efficiency can be enhanced by inflammatory cytokines. However, the existence of a physiological barrier, such as the blood-brain barrier and blood-testis barrier, allowing MSCs to home to the lesion by intravenous infusion is still limited and controversial [48]. Certainly, MSCs not only exert regenerative effects on the local environment but also reshape the systemic immune response to facilitate inflammation resolution via systemic immune cells $[23,49]$. Viruses with the GFP gene were transfected into MSCs to obtain $\mathrm{GFP}^{+}$MSCs. Then, $\mathrm{GFP}^{+} \mathrm{MSC}$ were primed by IL-1 $\beta$ (Figure S3A, B). The $\mathrm{GFP}^{+} \mathrm{MSC}$ were injected into CP/CPPS mice. We obtained the lung, liver, spleen and prostate on the first day after the injection of $\mathrm{GFP}^{+} \mathrm{MSC}$ and $\mathrm{GFP}^{+} \mathrm{IL}-1 \beta$-primed MSCs. GFP ${ }^{+} \mathrm{MSC}$ and $\mathrm{GFP}^{+}$IL-1 $\beta$-primed MSCs did not migrate to the prostate, as determined by flow cytometry and IF. Flow cytometry showed that GFP ${ }^{+} \mathrm{IL}-1 \beta$-primed MSCs engrafted in the spleen were more abundant than GFP ${ }^{+}$ MSCs, but this was not found in the prostate. There were no significant differences in MSC and IL-1 $\beta$ MSC engraftment into the lung or liver (Fig. 3A). IF showed that GFP ${ }^{+}$IL-1 $\beta$-primed MSCs engrafted in the spleen were more abundant than $\mathrm{GFP}^{+} \mathrm{MSC}$ and were not in the prostate. There were no significant differences in MSC and IL-1 $\beta$ MSC engraftment into the lung or liver (Fig. 3B). After the pretreatment of 
MSCs with IL-1 $\beta$, the expression of CXCR4 in MSCs increased, and we detected the protein CXCR4 gamete CXCL12 in the mouse spleen and prostate. It was found that CXCL12 was elevated in CP/CPPS mice. CXCL12 mRNA expression increased in the spleen of NOD-EAP mice (Fig. 3C). Western blotting showed increased expression of CXCL12 in the spleen of CP/CPPS mice (Fig. 3D). CXCL12 mRNA expression increased in the prostate of CP/CPPS mice (Fig. 3E). Western blotting showed increased expression of CXCL12 in the prostate of CP/CPPS mice (Fig. 3F; scale bar: $50 \mu \mathrm{m}$ ). Although the blood-prostate barrier may prevent MSC engraftment into the prostate, MSCs may have a therapeutic effect through systemic immunoregulation via splenic immune cells.

\section{After treatment with IL-1 $\beta$-primed MSCs, proinflammatory immune monocytes/macrophages decreased and anti-inflammatory immune Treg cells increased in the spleen, lung, bloodstream and prostate.}

Tissue monocytes are derived from CD11 $\mathrm{b}^{+}$monocytes in the spleen and blood [50, 51]. CD11 $\mathrm{b}^{+} \mathrm{Ly} 6 \mathrm{C}^{\text {high }}$ monocytes are inflammatory and play a critical role in the maintenance of inflammation [52]. In this study, the expression of $\mathrm{CD} 11 \mathrm{~b}^{+}$Ly $6 \mathrm{C}^{\text {high }}$ cells in the three groups of mice gradually decreased. The expression of Treg cells in the three groups of mice gradually increased. At the same time, the 13 inflammatory factors in the spleen and blood of mice showed that the inflammation in the saline, MSC and IL-1 $\beta$-primed MSC groups gradually decreased. The quantities of CD11 b $\mathrm{b}^{+} 6 \mathrm{C}^{\text {high }}$ cells gradually decreased in the spleens, blood, lungs and prostates (Fig. 4A) of the saline, MSC and IL-1 $\beta$-primed MSC groups. In addition, Treg cells are critical for resolving inflammation and secreting regenerative cytokines [53]. The quantities of $\mathrm{CD}^{+}{ }^{+} \mathrm{Foxp} 3^{+}$Treg cells gradually increased in the spleens, blood, lungs and prostates (Fig. 4B) of the saline, MSC and IL-1 $\beta$-primed MSC groups. Flow cytometry showed that the frequency of $C D 206^{+}$in $\mathrm{CD} 45^{+} \mathrm{CD} 4 / 80^{+}$macrophages gradually increased in the prostates of the MSC and IL-1 $\beta$-primed MSC groups. The frequency of $C D 86^{+} \mathrm{CD} 45+\mathrm{CD} 4 / 80+$ macrophages gradually decreased in the lungs of the MSC and IL-1 $\beta$-primed MSC groups (Fig. 5C). With three different treatments, the inflammatory factors gradually decreased in the spleens (Fig. 4D) and bloodstreams (Fig. $4 \mathrm{E}$ ) of the saline, MSC, and IL-1 $\beta$-primed MSC groups, as shown by the Biolegendplex ${ }^{\mathrm{TM}}$ inflammatory panel. Gate selection was presented (Figure S4). These proved MSCs have reshaped the systemic immune cells.

\section{Macrophage inflammatory properties changed from a proinflammatory phenotype to an anti- inflammatory phenotype in the prostate.}

Macrophages play a critical role in inflammation resolution and tissue healing [54,55]. The phenotype of prostate macrophages was changed via IL-1 $\beta$-primed MSC infusion. The expression of anti-inflammatory genes in in situ prostate macrophages increased after treatment, and the expression of proinflammatory genes decreased. The decreased quantities of proinflammatory macrophages in the prostate certified inflammation resolution via changes in the inflammatory properties of macrophages [54]. Flow cytometry showed that the frequencies of $\mathrm{CD} 206^{+}$and $\mathrm{Arg} 1^{+}$in $\mathrm{CD} 45+\mathrm{CD} 4 / 80+$ macrophages gradually increased in the prostates of the MSC and IL-1 $\beta$-primed MSC groups. In addition, the frequencies of $\mathrm{CD}^{2} 6^{+}$and 
iNOS $^{+}$in $\mathrm{CD}_{4} 5^{+} \mathrm{CD} 4 / 80^{+}$macrophages gradually decreased in the prostates of the MSC and IL-1 $\beta$-primed MSC group (Fig. 5A). IF showed that the expression of $\mathrm{CD}^{206^{+}}$macrophages gradually increased in the prostates of the MSC and IL-1 $\beta$-primed MSC groups (Fig. 5B). IF showed that the frequency of CD86 ${ }^{+}$ macrophages gradually decreased in the prostates of the MSC and IL-1 $\beta$-primed MSC groups (Fig. 5B). IF also showed that the frequency of $\mathrm{CD} 11 \mathrm{~b}^{+}$monocytes gradually decreased in the prostates of the MSC and IL-1 $\beta$-primed MSC groups (Fig. 5C). In-situ macrophages were extracted for RT-qPCR detection, and it was found that the expression of anti-inflammatory genes gradually increased in the MSC and IL-1 $\beta$ primed MSC groups (Fig. 5D). Macrophage gate selection was presented (Figure S5). The expression of proinflammatory genes gradually decreased in the saline, MSC and IL-1 $\beta$-primed MSC groups (Fig. 5D). The above findings might prove that although it is difficult to target MSCs to migrate to the prostate, MSCs can engraft to the spleen. IL-1 $\beta$-primed MSCs regulated inflammation resolution in the prostate via systemic immune cells.

\section{The expression of inflammation-related pathways decreased after treatment, and inflammation resolution was promoted.}

The NF-KB, signal transducer and activator of transcription 3 (STAT3) and MAPK pathways are very important in inflammation. The overexpression of these pathways can exacerbate and maintain inflammation $[56,57]$ and can be verified by detecting phosphorylated proteins. This study found that the inflammatory pathways NF-KB, STAT3 and MAPK were significantly downregulated via MSC infusion. Moreover, HE staining and inflammatory factor detection showed that inflammation was significantly decreased via MSC infusion. Western blot analysis demonstrated that p-STAT3, p-P65, p-JNK, p-ERK, and p-P38 were downregulated in the MSC-infused group (Fig. 6A). High expression of JNK/MAPK and NF-KB can promote the expression of inflammatory factors and the pain-related chemokine CCL2. The inflammation score of prostate tissue indicated that inflammation was reduced after treatment (Fig. 6B). The Biolegendplex ${ }^{\text {TM }}$ inflammatory panel indicated that inflammation in the prostate gradually decreased after treatment (Fig. 6C). The experimental protocol is presented in Figure S6.

\section{Pain-related indicators were relieved after treatment.}

Chemokines, such as CCL2 and CCL3, can increase the influx of $\mathrm{Ca}^{2+}$ ions in DRG receptors, which is a critical mechanism leading to chronic inflammatory pain $[58,59]$. Activation of the NF-KB and JNK/MAPK pathways leads to the overexpression of $\operatorname{CCL} 2[58,60,61]$. As shown in Fig. 6 , the above pathways were downregulated. In CP/CPPS mice, we measured the mRNA expression of the inflammatory chemokines CCL1, 2, 3, 4, 5, 7, 8, 13, 17, and 22. It was found that the expression of CCL2 mRNA in EAP mice was higher than that in control mice by RT-qPCR (Fig. 7A). The increase in CCL2 led to the activation of DRG by increasing $\mathrm{Ca}^{2+}$ influx. Through $\mathrm{Ca}^{2+}$ fluorescence, it was found that CCL2 can activate DRGs in a manner similar to capsaicin (Fig. 7B) and represent figures (Figure S7). After IL-1 $\beta$-primed MSC infusion, we found that mouse pelvic pain gradually decreased in the saline, MSC and IL-1 $\beta$-primed MSC groups through behavioral testing (Fig. 7C). Western blotting and IF showed that the expression of CCL2 in the prostate gradually decreased in the saline, MSC and IL-1 $\beta$-primed MSC groups (Fig. 7D, E). Calcitonin 
gene-related peptide (CGRP) and transient receptor potential cation channel subfamily $\mathrm{V}$ member 1 (TRPV1) overexpression in DRGs can maintain inflammatory pain and the activation of DRGs [62]. After MSC infusion, the expression of CGRP in DRGs gradually decreased (Fig. 7F). The expression of CCL2 and TRPV1 in DRGs gradually decreased (Fig. 8G). As shown in Fig. 6, MSCs and IL-1ß-primed MSCs reduced inflammation via the JNK/MAPK pathway. At the same time, the expression of the inflammatory pain chemokine CCL2 (a downstream product of the JNK/MAPK pathway) was reduced, which led to decreased activation of DRG nociceptors and pain relief. The study-related mechanism map is shown in Fig. 8.

\section{Discussion}

According to recent studies, MSCs have already been applied in inflammation-related diseases, so MSC infusion may become a new therapeutic strategy for CP/CPPS. Based on the limited immunomodulatory ability and homing efficiency of MSCs, we further used intravenous infusion of IL-1 $\beta$-primed MSCs for $\mathrm{CP} / \mathrm{CPPS}$. We found that its immunoregulatory and MSC-targeted engraftment efficiency on the systemic immune response and local lesions was enhanced by cytokines in CP/CPPS mice.

Currently, treatment options are available for CP/CPPS. In particular, drug therapy has significantly improved over the past decades [63]. At present, NSAIDs and corticosteroids, as the most acceptable therapy choices, could exert anti-inflammatory and symptom-relieving effects on CP/CPPS. However, most of these treatment options focus on the symptoms rather than etiology, and the therapeutic effect is still controversial [64]. Furthermore, these treatments inhibit immunoregulatory ability in all immune cells. This does not allow immune cells to play an immunoregulatory role to resolve inflammation. Therefore, novel strategies to address the disease are still needed. MSCs have emerged as a new therapeutic strategy in many inflammation-related diseases. The immunoregulatory ability of immune cells to restore immunological homeostasis has been widely studied by researchers [65]. Infused MSCs secrete immunoregulatory proteins, such as TSG-6, indoleamine 2,3-dioxygenase (IDO), and PGE-2, to regulate immune cell properties and deployment in the body [66-69]. However, the immunoregulatory ability and homing efficiency of MSCs are still limited [70]. Researchers have begun to find new ways to enhance the therapeutic effects of MSCs. For example, genetically engineered MSCs and cytokine-primed MSCs could endow MSCs with more meaningful therapeutic effects $[13,42,71]$. When MSCs are stimulated by cytokines, the NF-KB pathway in MSCs is activated. Accordingly, their downstream immunomodulatory proteins and chemokine receptors will be overexpressed [42, 47, 72-74]. This means that the targeted migration response to the chemokine capacity of MSCs is strengthened and the MSC homing efficiency is enhanced after cytokine priming $[47,74,75]$. These factors can enhance the immunomodulatory capacities of immune cells and restore the inflammatory microenvironment $[72,74,76]$. The expression of cytokines, such as IL-1 $\beta$, TNF- $\alpha$, and MIF, are boosted in inflammatory lesions and the body and recruit a large number of immune cells to maintain the inflammatory microenvironment $[77,78]$. Among them, IL-1 $\beta$ is widely increased in CP/CPPS patients and animal models; IL-1 $\beta$ is not only an important inflammatory factor to maintain prostatitis but also one of the main reasons for the maintenance of tissue inflammatory immune cell infiltration [77-79]. Because of its wide existence in inflammatory 
environments, it was our priming choice. In this study, the immunoregulatory ability of IL-1 $\beta$-primed MSCs to regulate the inflammatory properties of macrophages and promote the accumulation of Treg cells was enhanced in vitro. IL-1 $\beta$ primed MSC immunoregulation by regulating the inflammatory properties of macrophages, reducing the deployment of $C D 11 b^{+} L y 6 C^{\text {high }}$ monocytes and promoting the accumulation of Treg cells in the prostate.

As the largest peripheral immune organ of the body, the spleen is the main filter for blood-borne pathogens and antigens and stores a large population of monocytes and Treg cells [80,81]. These immune cells can affect the progression of inflammation and migrate among the spleen, bloodstream and local tissues in the body $[51,52]$. Under physiological conditions, CD11b + monocytes patrol the spleen, bloodstream and local tissue. $C D 11 b^{+} L y 6 C^{\text {high }}$ monocytes are inflammatory and migrate more often in inflammatory sites. Conversely, CD $11 \mathrm{~b}^{+} \mathrm{Ly} 6 \mathrm{C}^{\mathrm{low}}$ monocytes can play a role in the resolution of inflammation [82]. Treg cells also exert therapeutic effects on inflammation-related diseases via the resolution of inflammation [81]. The spleen is essential for systemic immunity, which intensively affects the local microenvironment. Proinflammatory immune cells and anti-inflammatory immune cells in the spleen, bloodstream and prostate are in dynamic equilibrium [83]. When inflammation occurs or inflammation improves, these immune cells can migrate to the local area to achieve proinflammatory or anti-inflammatory effects [82]. After the pretreatment of MSCs with IL-1 $\beta$, this study found that CXCR4 receptor expression in MSCs increased, and the targeted migration ability in response to CXCL12 was enhanced. However, IL-1 $\beta$-primed MSCs or MSCs failed to migrate to the prostate. The existence of the blood-prostate barrier may be the reason why CP/CPPS is difficult to treat. The blood-brain barrier-specific antigen EBA is also expressed in the prostate $[84,85]$. The prostate and blood vessels have a barrier similar to the blood-brain and blood-testis barriers $[85,86]$. Because capillary endothelial cells have special structures and functions, the final concentration of drugs and other therapeutic substances is lower in local tissue than in the bloodstream [87]. Therefore, this study restored the inflammatory microenvironment in the spleen, bloodstream, lung and prostate through the regulation of the systemic immune response via systemic immune cells. In this study, CD11 b ${ }^{+}$Ly $6 \mathrm{C}^{\text {high }}$ inflammatory monocytes were increased in the spleen, bloodstream, lung and prostate in a CP/CPPS systemic inflammatory environment. After IL-1 $\beta$-primed MSC infusion, CD11 $\mathrm{b}^{+} \mathrm{Ly} 6 \mathrm{C}^{\text {high }}$ monocytes were obviously decreased, and inflammation was decreased in the spleen, bloodstream and prostate. At the same time, the accumulation of Treg cells in the spleen, bloodstream and prostate was significantly increased. We restored the inflammatory microenvironment in the spleen, bloodstream, lung and prostate via IL-1 $\beta$ primed MSC infusion and engraftment to the spleen.

The inflammatory properties of macrophages are critical for restoring the inflammatory microenvironment in the prostate. In tissue, anti-inflammatory and proinflammatory macrophages are in dynamic equilibrium [88]. In inflammatory sites, the inflammatory phenotype of macrophages polarizes to proinflammatory macrophages. This leads to the exacerbation and maintenance of the inflammatory microenvironment. After IL-1 $\beta$-primed MSC infusion, the proinflammatory phenotype of macrophages polarized to an anti-inflammatory phenotype in lesion tissue [88]. In this study, immune cells restored the 
inflammatory microenvironment by MSCs regulating the systemic immune response via MSC engraftment in the spleen. This is due to the expression of PGE-2, TSG-6, interleukin 1 receptor antagonist (IL-RN), etc. in MSCs, which regulates the inflammatory phenotype of macrophages in remote or adjacent tissues $[43,73,89,90]$. In this study, immunomodulatory protein genes were overexpressed in IL-1 $\beta$ primed MSCs. In vitro, IL-1 $\beta$-primed MSCs regulated the inflammatory phenotype of macrophages. In vivo, infusion of IL-1 $\beta$-primed MSCs eventually regulated the inflammatory phenotype of macrophages and restored the inflammatory microenvironment in the prostate.

The most unbearable symptom of CP/CPPS patients is chronic pelvic pain. Inflammatory chemokines in the prostate are one of the main causes of chronic pelvic pain [91, 92]. The inflammatory pain-related chemokine CCL2 is also called MCP-1. Related studies have shown that CCL2 expression is increased in $\mathrm{CP} / \mathrm{CPPS}$ patients and mice $[61,93]$. When inflammation occurs in lesions, the overexpression of the NF$\mathrm{KB}$ and JNK/MAPK pathways leads to increased CCL2 secretion [94-98]. It can be used to recruit monocytes/macrophages and bind to DRG C-C motif chemokine receptor (CCR2), leading to the influx of $\mathrm{Ca}^{2+}$ in the DRG afferent channel, thereby causing the pain signal to be the same as that of capsaicin [59, 99]. DRGs themselves can also secrete CCL2 to stimulate the nerve conduction pathway of the spinal cord to further cause afferent pain and increase the expression of the TRPV1 nociceptive receptor [100102]. IL-1 $\beta$-primed MSC infusion relieved inflammation and regulated the NF-KB and JNK/MAPK pathways, further reducing the expression of CCL2 in local tissues and DRGs. These results proved that MSC therapy can alleviate pelvic pain in CP/CPPS.

In conclusion, we found that the IL-1 $\beta$-primed MSC immunoregulatory ability and MSC-targeted migration efficiency were enhanced. In addition, it was difficult for IL-1 $\beta$-primed MSCs to home to the prostate of CP/CPPS mice after MSC infusion. However, we found that IL-1 $\beta$-primed MSCs engrafted more in the spleen. They regulate local inflammation by reshaping the systemic immune response. Furthermore, the decreased production of the inflammatory chemokine CCL2 through the downregulation of the NF-KB and JNK/MAPK pathways by inflammatory resolution alleviates pain. This may provide a novel therapeutic strategy to explore MSCs with enhanced efficiency for inflammation resolution in CP/CPPS.

\section{Abbreviations}

CP/CPPS: Chronic prostatitis/chronic pelvic pain syndrome

MSCs: Mesenchymal stromal cells

IL-1 $\beta$ : Interleukin-1 $\beta$

EAP: Experimental autoimmune prostatitis

CCL2: Chemokine (C-C motif) ligand 2

TSG-6: TNF-stimulated gene 6 protein 
PGE-2: Prostaglandin E2

CXCR4: Chemokine C-X-C motif receptor 4

AVMA: American Veterinary Medical Association

NOD-EAP: Non-obesity diabetes-experimental autoimmune prostatitis

MAG: Male reproductive accessory gland

CFA: Complete Freund's adjuvant

DRGs: Dorsal root ganglia

CXCL12: Chemokine (C-X-Cmotif) ligand 12

IF: Immunofluorescence

HE: Hematoxylin-eosin

Arg1: Arginase 1

iNOS: Inducible nitric oxide synthase enzyme

IDO: Indoleamine 2,3-dioxygenase

IL-RN: Interleukin 1 receptor antagonist

CGRP: Calcitonin gene-related peptide

TRPV1: Transient receptor potential cation channel subfamily V member 1

\section{Declarations}

\section{Acknowledgments}

We acknowledgment Prof. Andy Peng Xiang and Xianguo Liu of Sun Yat-sen University for their constructive discussion and valuable advice in framing in the problem.

\section{Ethics approval and consent to participate}

Human umbilical cord samples were collected from six full-term newborns. All samples were collected with patient consent and signed informed consent. This study was approved by the Ethics Committee of the First Affiliated Hospital of Sun Yat-sen University (approval number: SYSU-IACUC-2018-168-1). All surgical procedures and postoperative nursing methods were approved by the Animal Care and Use Committee of Sun Yat-sen University (approval number: SYSU-IACUC-2021-000164). 


\section{Consent for publication}

All authors agree to the publication of the article.

\section{Availability of data and material}

The data and material to reproduce these findings are available from the authors by reasonable request.

\section{Funding}

This work was supported by the National Natural Science Foundation of China [81873829, M.Z.; 81671449, C.D.j].

\section{Competing interest}

The authors declare no conflicts of interest in this work.

\section{Author contribution}

Min Zhang: Conception and design, manuscript writing, and obtaining financial support; Chunhua Deng: Conception and design, manuscript writing, and obtaining financial support; Hanchao Liu: Conception and design, manuscript writing; Xinning Zhu: Conception and design and obtaining financial support; Ani Chi: Collection and assembly of data, data analysis and interpretation, and manuscript writing; Jian Dai: Collection and assembly of data, data analysis and interpretation, and manuscript writing; Zhenqing Wang: Collection and assembly of data, data analysis and interpretation, and manuscript writing.

\section{References}

1. Clemens JQ, Mullins C, Ackerman AL, Bavendam T, van Bokhoven A, Ellingson BM, et al. Urologic chronic pelvic pain syndrome: insights from the MAPP Research Network. Nat Rev Urol. 2019;16(3):187-200. doi: 10.1038/s41585-018-0135-5.

2. Engeler DS, Baranowski AP, Dinis-Oliveira P, Elneil S, Hughes J, Messelink EJ, et al. The 2013 EAU guidelines on chronic pelvic pain: is management of chronic pelvic pain a habit, a philosophy, or a science? 10 years of development. Eur Urol. 2013;64(3):431-9. doi: 10.1016/j.eururo.2013.04.035.

3. Franco JV, Turk T, Jung JH, Xiao YT, lakhno S, Tirapegui Fl, et al. Pharmacological interventions for treating chronic prostatitis/chronic pelvic pain syndrome. The Cochrane database of systematic reviews. 2019;10(10):Cd012552. doi: 10.1002/14651858.CD012552.pub2.

4. Liu Z, Murphy SF, Wong L, Schaeffer AJ, Thumbikat P. Neuronal/astrocytic expression of chemokine (C-C motif) ligand 2 is associated with monocyte/macrophage recruitment in male chronic pelvic pain. Pain. 2020;161(11):2581-91. doi: 10.1097/j.pain.0000000000001954.

5. Breser ML, Salazar FC, Rivero VE, Motrich RD. Immunological Mechanisms Underlying Chronic Pelvic Pain and Prostate Inflammation in Chronic Pelvic Pain Syndrome. Frontiers in immunology. 
2017;8:898. doi: 10.3389/fimmu.2017.00898.

6. Hore Z, Denk F. Neuroimmune interactions in chronic pain - An interdisciplinary perspective. Brain, behavior, and immunity. 2019;79:56-62. doi: 10.1016/j.bbi.2019.04.033.

7. Grace PM, Tawfik VL, Svensson Cl, Burton MD, Loggia ML, Hutchinson MR. The Neuroimmunology of Chronic Pain: From Rodents to Humans. The Journal of neuroscience : the official journal of the Society for Neuroscience. 2021;41(5):855-65. doi: 10.1523/jneurosci.1650-20.2020.

8. Mailhot B, Christin M, Tessandier N, Sotoudeh C, Bretheau F, Turmel R, et al. Neuronal interleukin-1 receptors mediate pain in chronic inflammatory diseases. The Journal of experimental medicine. 2020;217(9). doi: 10.1084/jem.20191430.

9. Nickel JC, Downey J, Clark J, Casey RW, Pommerville PJ, Barkin J, et al. Levofloxacin for chronic prostatitis/chronic pelvic pain syndrome in men: a randomized placebo-controlled multicenter trial. Urology. 2003;62(4):614-7. doi: 10.1016/s0090-4295(03)00583-1.

10. Bates S, Talbot M. Short course oral prednisolone therapy in chronic abacterial prostatitis and prostatodynia: case reports of three responders and one non-responder. Sexually transmitted infections. 2000;76(5):398-9. doi: 10.1136/sti.76.5.398.

11. Song N, Scholtemeijer M, Shah K. Mesenchymal Stem Cell Immunomodulation: Mechanisms and Therapeutic Potential. Trends in pharmacological sciences. 2020;41(9):653-64. doi: 10.1016/j.tips.2020.06.009.

12. Martin I, Galipeau J, Kessler C, Le Blanc K, Dazzi F. Challenges for mesenchymal stromal cell therapies. Sci Transl Med. 2019;11(480). doi: 10.1126/scitransImed.aat2189.

13. Levy O, Kuai R, Siren EMJ, Bhere D, Milton Y, Nissar N, et al. Shattering barriers toward clinically meaningful MSC therapies. Science advances. 2020;6(30):eaba6884. doi: 10.1126/sciadv.aba6884.

14. Ng KS, Kuncewicz TM, Karp JM. Beyond Hit-and-Run: Stem Cells Leave a Lasting Memory. Cell metabolism. 2015;22(4):541-3. doi: 10.1016/j.cmet.2015.09.019.

15. Naik S, Larsen SB, Cowley CJ, Fuchs E. Two to Tango: Dialog between Immunity and Stem Cells in Health and Disease. Cell. 2018;175(4):908-20. doi: 10.1016/j.cell.2018.08.071.

16. Li CX, Talele NP, Boo S, Koehler A, Knee-Walden E, Balestrini JL, et al. MicroRNA-21 preserves the fibrotic mechanical memory of mesenchymal stem cells. Nature materials. 2017;16(3):379-89. doi: 10.1038/nmat4780.

17. Shi Y, Wang Y, Li Q, Liu K, Hou J, Shao C, et al. Immunoregulatory mechanisms of mesenchymal stem and stromal cells in inflammatory diseases. Nature reviews Nephrology. 2018;14(8):493-507. doi: 10.1038/s41581-018-0023-5.

18. Koliaraki V, Prados A, Armaka M, Kollias G. The mesenchymal context in inflammation, immunity and cancer. Nature immunology. 2020;21(9):974-82. doi: 10.1038/s41590-020-0741-2.

19. Cheung TS, Dazzi F. Mesenchymal-myeloid interaction in the regulation of immunity. Seminars in immunology. 2018;35:59-68. doi: 10.1016/j.smim.2018.01.002. 
20. Nitzsche F, Müller C, Lukomska B, Jolkkonen J, Deten A, Boltze J. Concise Review: MSC Adhesion Cascade-Insights into Homing and Transendothelial Migration. Stem Cells. 2017;35(6):1446-60. doi: 10.1002/stem.2614.

21. Liesveld JL, Sharma N, Aljitawi OS. Stem cell homing: From physiology to therapeutics. Stem Cells. 2020;38(10):1241-53. doi: 10.1002/stem.3242.

22. Ullah M, Liu DD, Thakor AS. Mesenchymal Stromal Cell Homing: Mechanisms and Strategies for Improvement. iScience. 2019;15:421-38. doi: 10.1016/j.isci.2019.05.004.

23. Yang B, Hamilton JA, Valenzuela KS, Bogaerts A, Xi X, Aronowski J, et al. Multipotent Adult Progenitor Cells Enhance Recovery After Stroke by Modulating the Immune Response from the Spleen. Stem Cells. 2017;35(5):1290-302. doi: 10.1002/stem.2600.

24. Ko JH, Lee HJ, Jeong HJ, Kim MK, Wee WR, Yoon SO, et al. Mesenchymal stem/stromal cells precondition lung monocytes/macrophages to produce tolerance against allo- and autoimmunity in the eye. Proc Natl Acad Sci U S A. 2016;113(1):158-63. doi: 10.1073/pnas.1522905113.

25. Murphy N, Treacy O, Lynch K, Morcos M, Lohan P, Howard L, et al. TNF-a/IL-1 $\beta$-licensed mesenchymal stromal cells promote corneal allograft survival via myeloid cell-mediated induction of Foxp3(+) regulatory T cells in the lung. FASEB journal : official publication of the Federation of American Societies for Experimental Biology. 2019;33(8):9404-21. doi: 10.1096/fj.201900047R.

26. Huang Y, Wang J, Lai X, Qiu Y, Cai J, Ma Y, et al. Mesenchymal stromal cells attenuate post-stroke infection by preventing caspase-1-dependent splenic marginal zone B cell death. Signal transduction and targeted therapy. 2021;6(1):60. doi: 10.1038/s41392-020-00415-0.

27. Yi S, Han G, Shang Y, Liu C, Cui D, Yu S, et al. Microbubble-mediated ultrasound promotes accumulation of bone marrow mesenchymal stem cell to the prostate for treating chronic bacterial prostatitis in rats. Sci Rep. 2016;6:19745. doi: 10.1038/srep19745.

28. Chao K, Zhang S, Qiu Y, Chen X, Zhang X, Cai C, et al. Correction to: Human umbilical cord-derived mesenchymal stem cells protect against experimental colitis via CD5+ B regulatory cells. Stem Cell Res Ther. 2019;10(1):33. doi: 10.1186/s13287-019-1132-1.

29. Rivero VE, Cailleau C, Depiante-Depaoli M, Riera CM, Carnaud C. Non-obese diabetic (NOD) mice are genetically susceptible to experimental autoimmune prostatitis (EAP). Journal of autoimmunity. 1998;11(6):603-10. doi: 10.1006/jaut.1998.0248.

30. Zhang LG, Yu ZQ, Yang C, Chen J, Zhan CS, Chen XG, et al. Effect of Eriocalyxin B on prostatic inflammation and pelvic pain in a mouse model of experimental autoimmune prostatitis. Prostate. 2020;80(16):1394-404. doi: 10.1002/pros.24065.

31. Quick ML, Done JD, Thumbikat P. Measurement of tactile allodynia in a murine model of bacterial prostatitis. Journal of visualized experiments : JoVE. 2013(71):e50158. doi: 10.3791/50158.

32. Laird JMA, Martinez-Caro L, Garcia-Nicas E, Cervero F. A new model of visceral pain and referred hyperalgesia in the mouse. Pain. 2001;92(3):335-42. doi: 10.1016/s0304-3959(01)00275-5.

33. Chaplan SR, Bach FW, Pogrel JW, Chung JM, Yaksh TL. Quantitative assessment of tactile allodynia in the rat paw. Journal of neuroscience methods. 1994;53(1):55-63. doi: 10.1016/0165- 
0270(94)90144-9.

34. Shi R, Xu JW, Xiao ZT, Chen RF, Zhang YL, Lin JB, et al. Naringin and Naringenin Relax Rat Tracheal Smooth by Regulating BK(Ca) Activation. Journal of medicinal food. 2019;22(9):963-70. doi: 10.1089/jmf.2018.4364.

35. Asada K, Obata K, Horiguchi K, Takaki M. Age-related changes in afferent responses in sensory neurons to mechanical stimulation of osteoblasts in coculture system. American journal of physiology Cell physiology. 2012;302(5):C757-65. doi: 10.1152/ajpcell.00362.2011.

36. Rudick CN, Schaeffer AJ, Thumbikat P. Experimental autoimmune prostatitis induces chronic pelvic pain. American journal of physiology Regulatory, integrative and comparative physiology. 2008;294(4):R1268-75. doi: 10.1152/ajpregu.00836.2007.

37. Vykhovanets EV, Resnick MI, MacLennan GT, Gupta S. Experimental rodent models of prostatitis: limitations and potential. Prostate cancer and prostatic diseases. 2007;10(1):15-29. doi: 10.1038/sj.pcan.4500930.

38. García JR, Quirós M, Han WM, O'Leary MN, Cox GN, Nusrat A, et al. IFN-y-tethered hydrogels enhance mesenchymal stem cell-based immunomodulation and promote tissue repair. Biomaterials. 2019;220:119403. doi: 10.1016/j.biomaterials.2019.119403.

39. Magne B, Dedier M, Nivet M, Coulomb B, Banzet S, Lataillade JJ, et al. IL-1 $\beta$-Primed Mesenchymal Stromal Cells Improve Epidermal Substitute Engraftment and Wound Healing via Matrix Metalloproteinases and Transforming Growth Factor- $\beta 1$. The Journal of investigative dermatology. 2020;140(3):688-98.e21. doi: 10.1016/j.jid.2019.07.721.

40. Hu S, Yuan J, Xu J, Li X, Zhang G, Ma Q, et al. TNF-a and IFN- $\gamma$ synergistically inhibit the repairing ability of mesenchymal stem cells on mice colitis and colon cancer. American journal of translational research. 2019;11(9):6207-20.

41. Ren K, Torres R. Role of interleukin-1beta during pain and inflammation. Brain research reviews. 2009;60(1):57-64. doi: 10.1016/j.brainresrev.2008.12.020.

42. Németh K, Leelahavanichkul A, Yuen PS, Mayer B, Parmelee A, Doi K, et al. Bone marrow stromal cells attenuate sepsis via prostaglandin $\mathrm{E}(2)$-dependent reprogramming of host macrophages to increase their interleukin-10 production. Nature medicine. 2009;15(1):42-9. doi: 10.1038/nm.1905.

43. Choi H, Lee RH, Bazhanov N, Oh JY, Prockop DJ. Anti-inflammatory protein TSG-6 secreted by activated MSCs attenuates zymosan-induced mouse peritonitis by decreasing TLR2/NF-KB signaling in resident macrophages. Blood. 2011;118(2):330-8. doi: 10.1182/blood-2010-12-327353.

44. Zheng J, Li H, He L, Huang Y, Cai J, Chen L, et al. Preconditioning of umbilical cord-derived mesenchymal stem cells by rapamycin increases cell migration and ameliorates liver ischaemia/reperfusion injury in mice via the CXCR4/CXCL12 axis. Cell Prolif. 2019;52(2):e12546. doi: $10.1111 /$ cpr.12546.

45. Kao AP, Wang KH, Long CY, Chai CY, Tsai CF, Hsieh TH, et al. Interleukin-1 $\beta$ induces cyclooxygenase-2 expression and promotes the invasive ability of human mesenchymal stem cells derived from ovarian endometrioma. Fertil Steril. 2011;96(3):678-84.e1. doi: 10.1016/j.fertnstert.2011.06.041. 
46. Liu X, Duan B, Cheng Z, Jia X, Mao L, Fu H, et al. SDF-1/CXCR4 axis modulates bone marrow mesenchymal stem cell apoptosis, migration and cytokine secretion. Protein \& cell. 2011;2(10):84554. doi: 10.1007/s13238-011-1097-z.

47. Fan H, Zhao G, Liu L, Liu F, Gong W, Liu X, et al. Pre-treatment with IL-1 $\beta$ enhances the efficacy of MSC transplantation in DSS-induced colitis. Cellular \& molecular immunology. 2012;9(6):473-81. doi: 10.1038/cmi.2012.40.

48. Kwon S, Yoo KH, Sym SJ, Khang D. Mesenchymal stem cell therapy assisted by nanotechnology: a possible combinational treatment for brain tumor and central nerve regeneration. International journal of nanomedicine. 2019;14:5925-42. doi: 10.2147/ijn.S217923.

49. Hu J, Zhang L, Wang N, Ding R, Cui S, Zhu F, et al. Mesenchymal stem cells attenuate ischemic acute kidney injury by inducing regulatory $\mathrm{T}$ cells through splenocyte interactions. Kidney international. 2013;84(3):521-31. doi: 10.1038/ki.2013.114.

50. Guilliams M, Mildner A, Yona S. Developmental and Functional Heterogeneity of Monocytes. Immunity. 2018;49(4):595-613. doi: 10.1016/j.immuni.2018.10.005.

51. Ley K, Laudanna C, Cybulsky MI, Nourshargh S. Getting to the site of inflammation: the leukocyte adhesion cascade updated. Nature reviews Immunology. 2007;7(9):678-89. doi: 10.1038/nri2156.

52. Luster $A D$, Alon $R$, von Andrian $U H$. Immune cell migration in inflammation: present and future therapeutic targets. Nature immunology. 2005;6(12):1182-90. doi: 10.1038/ni1275.

53. D'Alessio FR, Kurzhagen JT, Rabb H. Reparative T lymphocytes in organ injury. J Clin Invest. 2019;129(7):2608-18. doi: 10.1172/jci124614.

54. Wynn TA, Vannella KM. Macrophages in Tissue Repair, Regeneration, and Fibrosis. Immunity. 2016;44(3):450-62. doi: 10.1016/j.immuni.2016.02.015.

55. Watanabe S, Alexander M, Misharin AV, Budinger GRS. The role of macrophages in the resolution of inflammation. J Clin Invest. 2019;129(7):2619-28. doi: 10.1172/jci124615.

56. Li HS, Watowich SS. Innate immune regulation by STAT-mediated transcriptional mechanisms. Immunological reviews. 2014;261(1):84-101. doi: 10.1111/imr.12198.

57. Chen LF, Greene WC. Shaping the nuclear action of NF-kappaB. Nature reviews Molecular cell biology. 2004;5(5):392-401. doi: 10.1038/nrm1368.

58. Zhang N, Inan S, Cowan A, Sun R, Wang JM, Rogers TJ, et al. A proinflammatory chemokine, CCL3, sensitizes the heat- and capsaicin-gated ion channel TRPV1. Proc Natl Acad Sci U S A. 2005;102(12):4536-41. doi: 10.1073/pnas.0406030102.

59. Wang K, Gu Y, Liao Y, Bang S, Donnelly CR, Chen O, et al. PD-1 blockade inhibits osteoclast formation and murine bone cancer pain. J Clin Invest. 2020;130(7):3603-20. doi: 10.1172/jci133334.

60. Griffith JW, Sokol CL, Luster AD. Chemokines and chemokine receptors: positioning cells for host defense and immunity. Annual review of immunology. 2014;32:659-702. doi: 10.1146/annurevimmunol-032713-120145. 
61. Desireddi NV, Campbell PL, Stern JA, Sobkoviak R, Chuai S, Shahrara S, et al. Monocyte chemoattractant protein-1 and macrophage inflammatory protein-1alpha as possible biomarkers for the chronic pelvic pain syndrome. J Urol. 2008;179(5):1857-61; discussion 61-2. doi: 10.1016/j.juro.2008.01.028.

62. Fattori V, Pinho-Ribeiro FA, Staurengo-Ferrari L, Borghi SM, Rossaneis AC, Casagrande R, et al. The specialised pro-resolving lipid mediator maresin 1 reduces inflammatory pain with a long-lasting analgesic effect. British journal of pharmacology. 2019;176(11):1728-44. doi: 10.1111/bph.14647.

63. Anothaisintawee T, Attia J, Nickel JC, Thammakraisorn S, Numthavaj P, McEvoy M, et al. Management of chronic prostatitis/chronic pelvic pain syndrome: a systematic review and network meta-analysis. Jama. 2011;305(1):78-86. doi: 10.1001/jama.2010.1913.

64. Anderson RU, Nathanson BH. Pain: drug therapies for CP/CPPS: help or hype? Nat Rev Urol. 2011;8(5):236-7. doi: 10.1038/nrurol.2011.51.

65. Bernardo ME, Fibbe WE. Mesenchymal stromal cells: sensors and switchers of inflammation. Cell Stem Cell. 2013;13(4):392-402. doi: 10.1016/j.stem.2013.09.006.

66. Mittal M, Tiruppathi C, Nepal S, Zhao YY, Grzych D, Soni D, et al. TNFa-stimulated gene-6 (TSG6) activates macrophage phenotype transition to prevent inflammatory lung injury. Proc Natl Acad Sci U S A. 2016;113(50):E8151-e8. doi: 10.1073/pnas.1614935113.

67. Song HB, Park SY, Ko JH, Park JW, Yoon CH, Kim DH, et al. Mesenchymal Stromal Cells Inhibit Inflammatory Lymphangiogenesis in the Cornea by Suppressing Macrophage in a TSG-6-Dependent Manner. Molecular therapy : the journal of the American Society of Gene Therapy. 2018;26(1):162-72. doi: 10.1016/j.ymthe.2017.09.026.

68. Su J, Chen X, Huang Y, Li W, Li J, Cao K, et al. Phylogenetic distinction of iNOS and IDO function in mesenchymal stem cell-mediated immunosuppression in mammalian species. Cell death and differentiation. 2014;21(3):388-96. doi: 10.1038/cdd.2013.149.

69. Aggarwal S, Pittenger MF. Human mesenchymal stem cells modulate allogeneic immune cell responses. Blood. 2005;105(4):1815-22. doi: 10.1182/blood-2004-04-1559.

70. Galipeau J, Sensébé L. Mesenchymal Stromal Cells: Clinical Challenges and Therapeutic Opportunities. Cell Stem Cell. 2018;22(6):824-33. doi: 10.1016/j.stem.2018.05.004.

71. An JH, Li Q, Bhang DH, Song WJ, Youn HY. TNF-a and INF-y primed canine stem cell-derived extracellular vesicles alleviate experimental murine colitis. Sci Rep. 2020;10(1):2115. doi: 10.1038/s41598-020-58909-4.

72. Liu Q, Ji S, Xia T, Liu J, Liu Z, Chen X, et al. MCP-1 Priming Enhanced the Therapeutic Effects of Human Mesenchymal Stromal Cells on Contact Hypersensitivity Mice by Activating the COX2PGE2/STAT3 Pathway. Stem Cells Dev. 2020;29(16):1073-83. doi: 10.1089/scd.2020.0035.

73. Lee RH, Pulin AA, Seo MJ, Kota DJ, Ylostalo J, Larson BL, et al. Intravenous hMSCs improve myocardial infarction in mice because cells embolized in lung are activated to secrete the antiinflammatory protein TSG-6. Cell Stem Cell. 2009;5(1):54-63. doi: 10.1016/j.stem.2009.05.003. 
74. Oh JY, Roddy GW, Choi H, Lee RH, Ylöstalo JH, Rosa RH, Jr., et al. Anti-inflammatory protein TSG-6 reduces inflammatory damage to the cornea following chemical and mechanical injury. Proc Natl Acad Sci U S A. 2010;107(39):16875-80. doi: 10.1073/pnas.1012451107.

75. Nie H, An F, Mei J, Yang C, Zhan Q, Zhang Q. IL-1 $\beta$ Pretreatment Improves the Efficacy of Mesenchymal Stem Cells on Acute Liver Failure by Enhancing CXCR4 Expression. Stem Cells Int. 2020;2020:1498315. doi: 10.1155/2020/1498315.

76. Mindrescu C, Dias AA, Olszewski RJ, Klein MJ, Reis LF, Wisniewski HG. Reduced susceptibility to collagen-induced arthritis in DBA/1J mice expressing the TSG-6 transgene. Arthritis and rheumatism. 2002;46(9):2453-64. doi: 10.1002/art.10503.

77. Lundh D, Hedelin H, Jonsson K, Gifford M, Larsson D. Assessing chronic pelvic pain syndrome patients: blood plasma factors and cortisol saliva. Scandinavian journal of urology. 2013;47(6):5218. doi: 10.3109/21681805.2013.769460.

78. Alexander RB, Ponniah S, Hasday J, Hebel JR. Elevated levels of proinflammatory cytokines in the semen of patients with chronic prostatitis/chronic pelvic pain syndrome. Urology. 1998;52(5):744-9. doi: 10.1016/s0090-4295(98)00390-2.

79. Ho DR, Chang PJ, Lin WY, Huang YC, Lin JH, Huang KT, et al. Beneficial Effects of Inflammatory Cytokine-Targeting Aptamers in an Animal Model of Chronic Prostatitis. Int J Mol Sci. 2020;21(11). doi: 10.3390/ijms21113953.

80. Bronte $\mathrm{V}$, Pittet MJ. The spleen in local and systemic regulation of immunity. Immunity. 2013;39(5):806-18. doi: 10.1016/j.immuni.2013.10.010.

81. Richards DM, Delacher M, Goldfarb Y, Kägebein D, Hofer AC, Abramson J, et al. Treg Cell Differentiation: From Thymus to Peripheral Tissue. Progress in molecular biology and translational science. 2015;136:175-205. doi: 10.1016/bs.pmbts.2015.07.014.

82. Swirski FK, Nahrendorf M, Etzrodt M, Wildgruber M, Cortez-Retamozo V, Panizzi P, et al. Identification of splenic reservoir monocytes and their deployment to inflammatory sites. Science. 2009;325(5940):612-6. doi: 10.1126/science.1175202.

83. Mebius RE, Kraal G. Structure and function of the spleen. Nature reviews Immunology. 2005;5(8):60616. doi: $10.1038 /$ nri1669.

84. Ghabriel MN, Lu JJ, Hermanis G, Zhu C, Setchell BP. Expression of a blood-brain barrier-specific antigen in the reproductive tract of the male rat. Reproduction. 2002;123(3):389-97. doi: 10.1530/rep.0.1230389.

85. Nga VD, Lim J, Choy DK, Nyein MA, Lu J, Chou N, et al. Effects of polycaprolactone-based scaffolds on the blood-brain barrier and cerebral inflammation. Tissue engineering Part A. 2015;21(3-4):647-53. doi: 10.1089/ten.TEA.2013.0779.

86. Shang Y, Cui D, Yi S. Opening tight junctions may be key to opening the blood-prostate barrier. Med Sci Monit. 2014;20:2504-7. doi: 10.12659/msm.890902.

87. Fulmer BR, Turner TT. A blood-prostate barrier restricts cell and molecular movement across the rat ventral prostate epithelium. J Urol. 2000;163(5):1591-4. 
88. Jiang W, Xu J. Immune modulation by mesenchymal stem cells. Cell Prolif. 2020;53(1):e12712. doi: 10.1111/cpr.12712.

89. Luz-Crawford P, Djouad F, Toupet K, Bony C, Franquesa M, Hoogduijn MJ, et al. Mesenchymal Stem Cell-Derived Interleukin 1 Receptor Antagonist Promotes Macrophage Polarization and Inhibits B Cell Differentiation. Stem Cells. 2016;34(2):483-92. doi: 10.1002/stem.2254.

90. Ylöstalo JH, Bartosh TJ, Coble K, Prockop DJ. Human mesenchymal stem/stromal cells cultured as spheroids are self-activated to produce prostaglandin E2 that directs stimulated macrophages into an anti-inflammatory phenotype. Stem Cells. 2012;30(10):2283-96. doi: 10.1002/stem.1191.

91. Jung $H$, Toth PT, White FA, Miller RJ. Monocyte chemoattractant protein-1 functions as a neuromodulator in dorsal root ganglia neurons. Journal of neurochemistry. 2008;104(1):254-63. doi: 10.1111/j.1471-4159.2007.04969.x.

92. Murphy SF, Schaeffer AJ, Thumbikat P. Immune mediators of chronic pelvic pain syndrome. Nat Rev Urol. 2014;11(5):259-69. doi: 10.1038/nrurol.2014.63.

93. Quick ML, Mukherjee S, Rudick CN, Done JD, Schaeffer AJ, Thumbikat P. CCL2 and CCL3 are essential mediators of pelvic pain in experimental autoimmune prostatitis. American journal of physiology Regulatory, integrative and comparative physiology. 2012;303(6):R580-9. doi:

10.1152/ajpregu.00240.2012.

94. Jiang BC, Liu T, Gao YJ. Chemokines in chronic pain: cellular and molecular mechanisms and therapeutic potential. Pharmacology \& therapeutics. 2020;212:107581. doi: 10.1016/j.pharmthera.2020.107581.

95. Meng LQ, Yang FY, Wang MS, Shi BK, Chen DX, Chen D, et al. Quercetin protects against chronic prostatitis in rat model through NF-KB and MAPK signaling pathways. Prostate. 2018;78(11):790800. doi: 10.1002 /pros. 23536 .

96. Abbadie C, Bhangoo S, De Koninck Y, Malcangio M, Melik-Parsadaniantz S, White FA. Chemokines and pain mechanisms. Brain research reviews. 2009;60(1):125-34. doi:

10.1016/j.brainresrev.2008.12.002.

97. Gao YJ, Zhang L, Samad OA, Suter MR, Yasuhiko K, Xu ZZ, et al. JNK-induced MCP-1 production in spinal cord astrocytes contributes to central sensitization and neuropathic pain. The Journal of neuroscience : the official journal of the Society for Neuroscience. 2009;29(13):4096-108. doi: 10.1523/jneurosci.3623-08.2009.

98. Kobayashi M, Mikami D, Kimura H, Kamiyama K, Morikawa Y, Yokoi S, et al. Short-chain fatty acids, GPR41 and GPR43 ligands, inhibit TNF-a-induced MCP-1 expression by modulating p38 and JNK signaling pathways in human renal cortical epithelial cells. Biochemical and biophysical research communications. 2017;486(2):499-505. doi: 10.1016/j.bbrc.2017.03.071.

99. Xie RG, Gao YJ, Park CK, Lu N, Luo C, Wang WT, et al. Spinal CCL2 Promotes Central Sensitization, Long-Term Potentiation, and Inflammatory Pain via CCR2: Further Insights into Molecular, Synaptic, and Cellular Mechanisms. Neuroscience bulletin. 2018;34(1):13-21. doi: 10.1007/s12264-017-01065 . 
100. Kao DJ, Li AH, Chen JC, Luo RS, Chen YL, Lu JC, et al. CC chemokine ligand 2 upregulates the current density and expression of TRPV1 channels and Nav1.8 sodium channels in dorsal root ganglion neurons. Journal of neuroinflammation. 2012;9:189. doi: 10.1186/1742-2094-9-189.

101. Jiang H, Cui H, Wang T, Shimada SG, Sun R, Tan Z, et al. CCL2/CCR2 signaling elicits itch- and painlike behavior in a murine model of allergic contact dermatitis. Brain, behavior, and immunity. 2019;80:464-73. doi: 10.1016/j.bbi.2019.04.026.

102. Van Steenwinckel J, Reaux-Le Goazigo A, Pommier B, Mauborgne A, Dansereau MA, Kitabgi P, et al. CCL2 released from neuronal synaptic vesicles in the spinal cord is a major mediator of local inflammation and pain after peripheral nerve injury. The Journal of neuroscience : the official journal of the Society for Neuroscience. 2011;31(15):5865-75. doi: 10.1523/jneurosci.5986-10.2011.

\section{Figures}


A
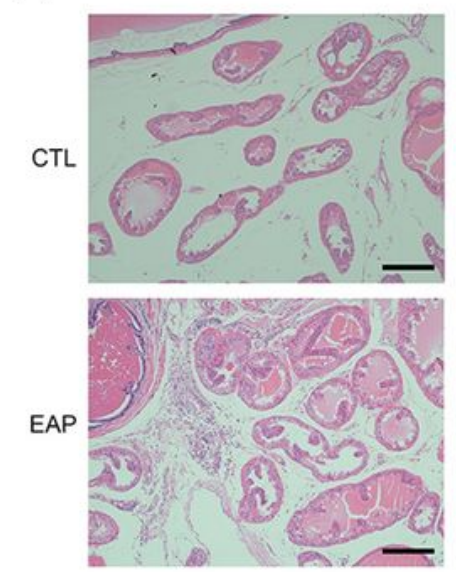

C
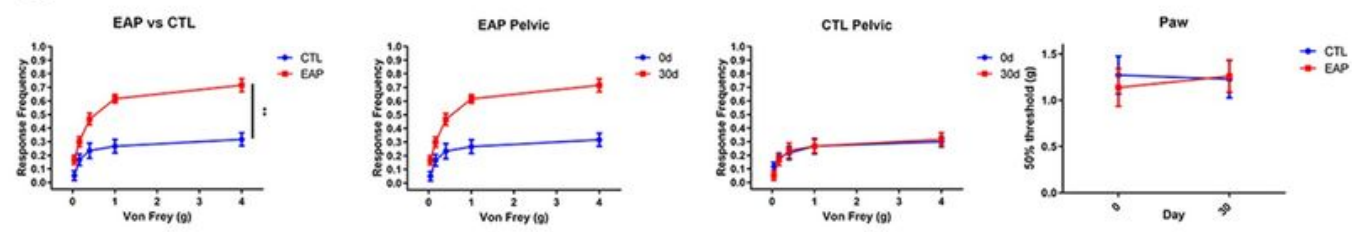

D

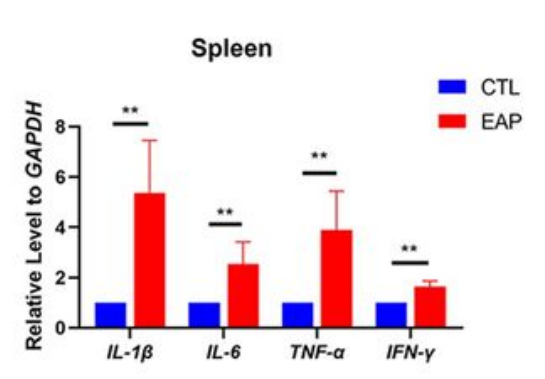

E
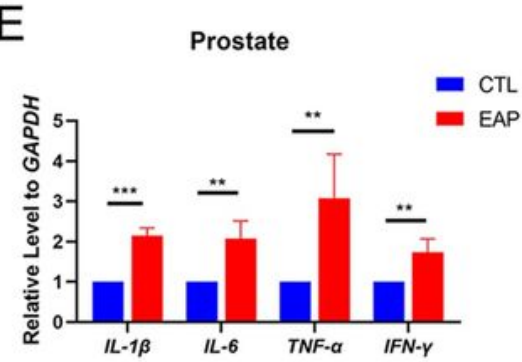

F

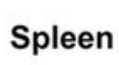

G

Prostate

$\mathrm{H}$
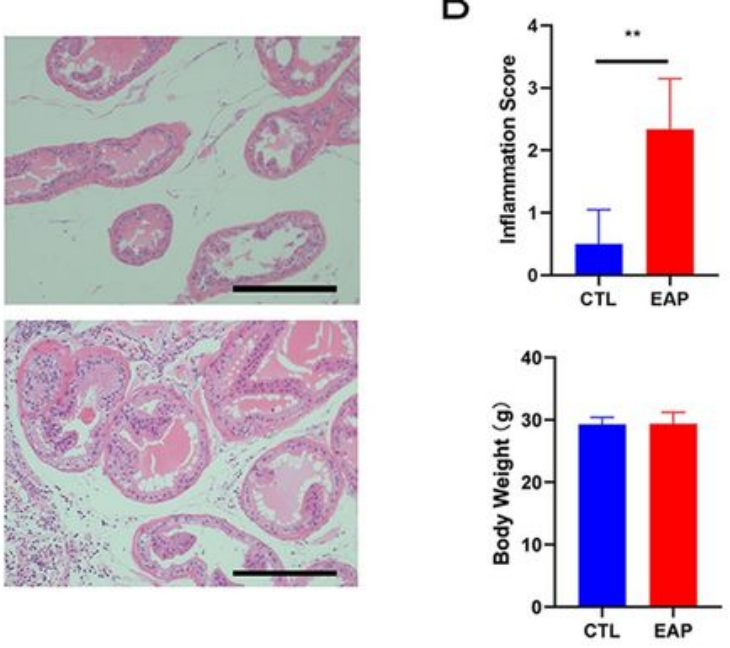

.

. 
CP/CPPS mice and control mice by RT-qPCR. F. IL-1 $\beta$ protein expression in the spleen of CP/CPPS mice and control mice by Western blotting ( $n=6$ per group). G. IL-1 $\beta$ protein expression in the prostate of CP/CPPS mice and control mice by Western blotting. H. IL-1 $\beta$ protein expression in the bloodstream of CP/CPPS mice and control mice by LegendplexTM bead-based immunoassays ( $n=6$ per group). Error bars indicate SD. ${ }^{*} p<0.05,{ }^{* *} p<0.01,{ }^{* *} p<0.001$.
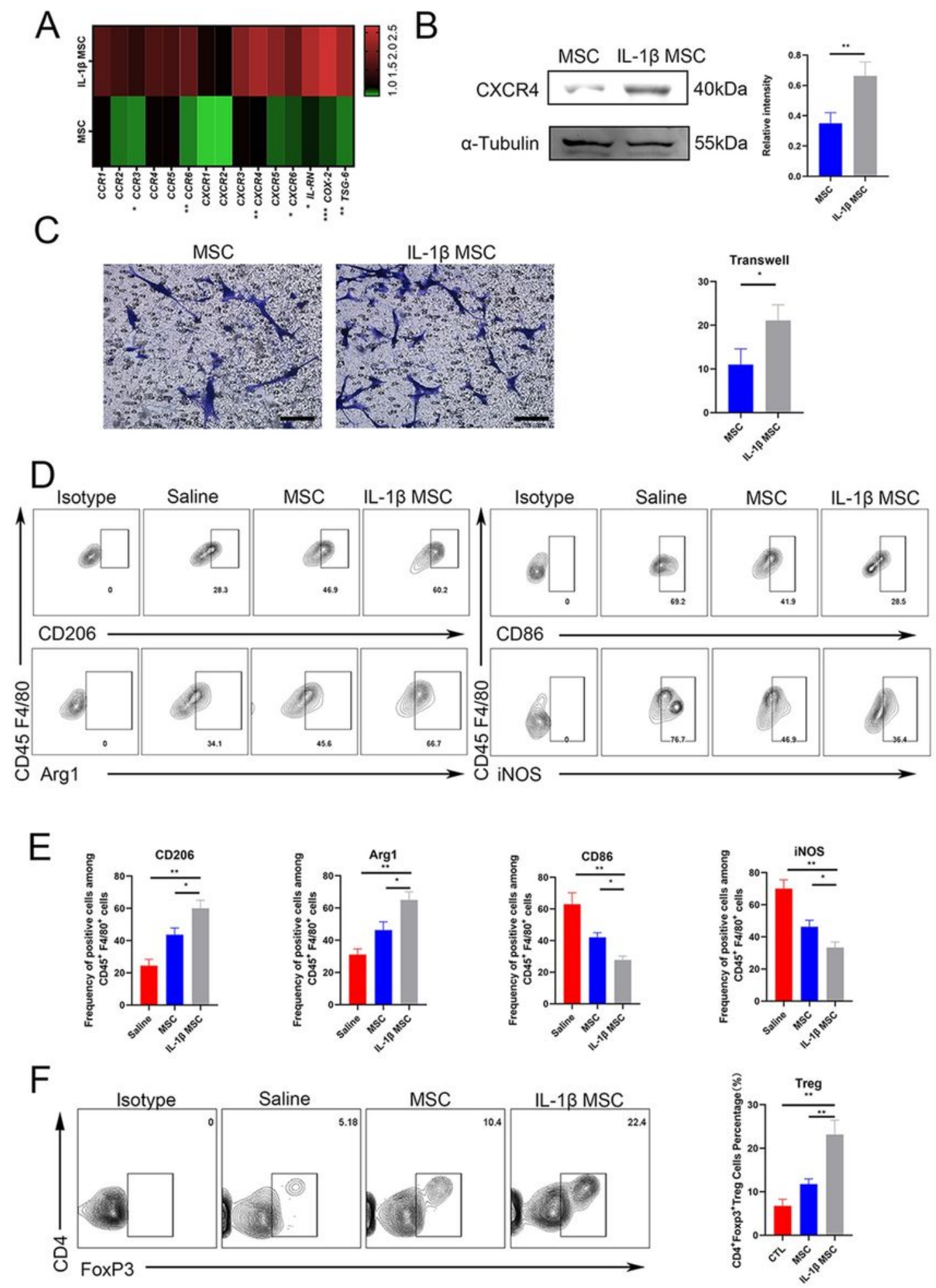

Figure 2 
IL-1 $\beta$-primed MSCs showed better immune regulation ability and targeted migration ability than MSCs in vitro. A. The expression of CXCR4, COX-2, TSG- 6 and some other genes was checked by RT-qPCR in MSCs and IL-1 $\beta$-primed MSCs ( $n=3$ per group). B. IL-1 $\beta$-primed MSCs and MSCs expressing the CXCR4 protein were assessed by Western blotting ( $n=3$ per group). C. The migration ability of IL-1 $\beta$-primed MSCs and MSCs targeting CXCL12 was assessed by Transwell assays ( $n=3$ per group) (bar $=100 \mu \mathrm{m})$. D. Inflammatory properties: Representative flow cytometry histograms of macrophages with CD206, Arg1, CD86, and iNOS in the saline, MSC and IL-1 $\beta$-primed MSC groups were detected by flow cytometry $(n=3$ per group). E. Statistical histograms of macrophages with CD206+, Arg1+, CD86+, and iNOS+ quantitative analysis in the saline, MSC and IL-1 $\beta$-primed MSC groups. F. The proportion of CD4+FoxP3+ Treg cells in the saline, MSC, and IL-1 $\beta$-primed MSC groups were detected by flow cytometry $(n=3$ per group). Error bars indicate SD. ${ }^{\star} p<0.05,{ }^{\star \star} p<0.01,{ }^{\star \star \star} p<0.001$. 

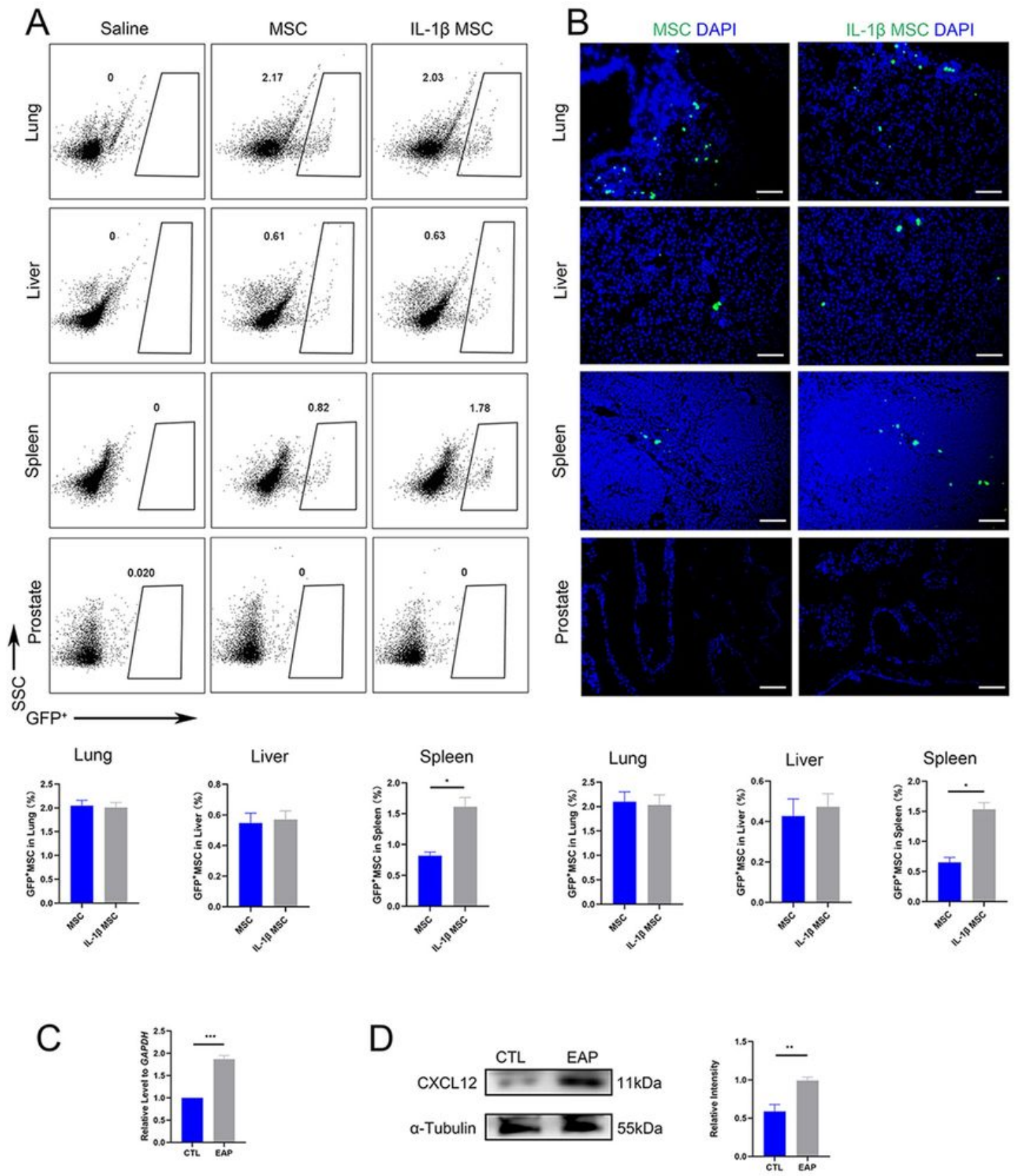

$\mathrm{E}$
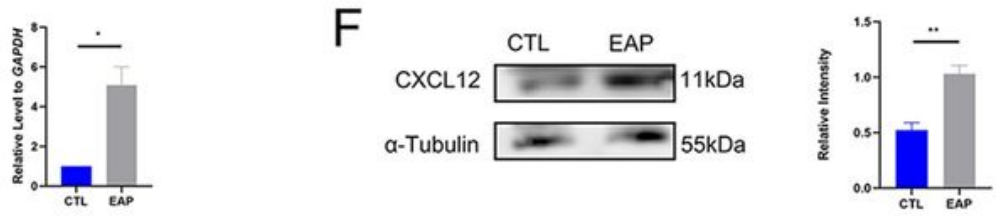

\section{Figure 3}

IL-1 $\beta$-primed MSCs migrated to the spleen more than MSCs. A. GFP+ IL-1 $\beta$-primed MSCs and GFP+ MSCs were recruited to the lungs, livers, spleens and prostates of EAP mice by flow cytometry ( $n=6$ per group). B. GFP+ IL-1 $\beta$-primed MSCs and GFP+ MSCs were recruited to the lungs, livers, spleens and prostates of EAP mice by IF (bar $=100 \mu \mathrm{m})(\mathrm{n}=6$ per group). C. CXCL12 mRNA expression in the spleens of EAP mice and control mice by RT-qPCR ( $\mathrm{n}=6$ per group). D. CXCL12 protein expression in the spleens of EAP mice 
and control mice by Western blotting ( $\mathrm{n}=6$ per group). E. CXCL12 mRNA expression in the prostates of EAP mice and control mice by RT-qPCR ( $n=6$ per group). F. CXCL12 protein expression in the prostates of EAP mice and control mice by Western blotting ( $n=6$ per group). Error bars indicate $S D .{ }^{*} p<0.05,{ }^{*} p<$ $0.01, * * * p<0.001$.
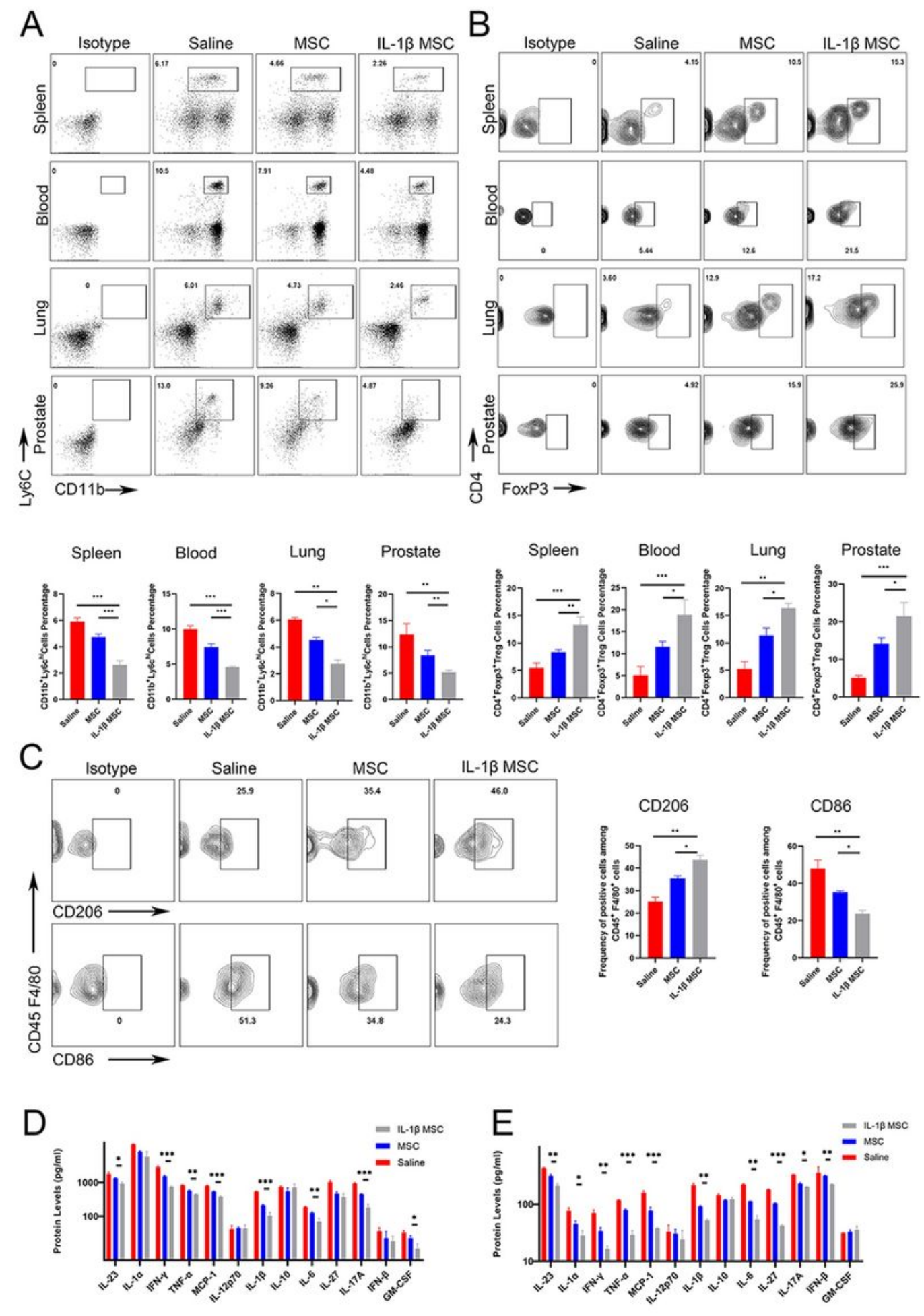

Figure 4 
Proinflammatory immune monocytes/macrophages decreased and anti-inflammatory Treg cells increased in the spleen, bloodstream, lung and prostate after injection of MSCs and IL-1 $\beta$-primed MSCs. A. Proportion of CD11b+ Ly6Chigh cells in the spleens, bloodstreams, lungs, and prostates of the saline, MSC and IL-1 $\beta$-primed MSC groups by flow cytometry ( $n=6$ per group). $B$. The proportion of CD4+Foxp3+ Treg cells in the spleens, bloodstreams, lungs, and prostates of the saline, MSC and IL-1 $\beta$ primed MSC groups ( $n=6$ per group). C. The proportion of CD206+CD45+F4/80+ macrophages in the lungs of the saline, MSC and IL-1 $\beta$-primed MSC groups, as determined by flow cytometry. The proportion of CD86+ CD45+F4/80+ macrophages in the lungs of the saline, MSC and IL-1 $\beta$-primed MSC groups, as determined by flow cytometry ( $n=6$ per group). $D$. Inflammatory factor protein expression in the spleens of the saline, MSC, and IL-1 $\beta$-primed MSC groups by BiolegendplexTM bead-based immunoassays ( $n=6$ per group). E. Expression of inflammatory factors in the bloodstreams of the saline, MSC, and IL-1 $\beta$ primed MSC groups by BiolegendplexTM bead-based immunoassays ( $n=6$ per group). Error bars indicate SD. ${ }^{*} p<0.05,{ }^{*} p<0.01, * \star * p<0.001$. 
A
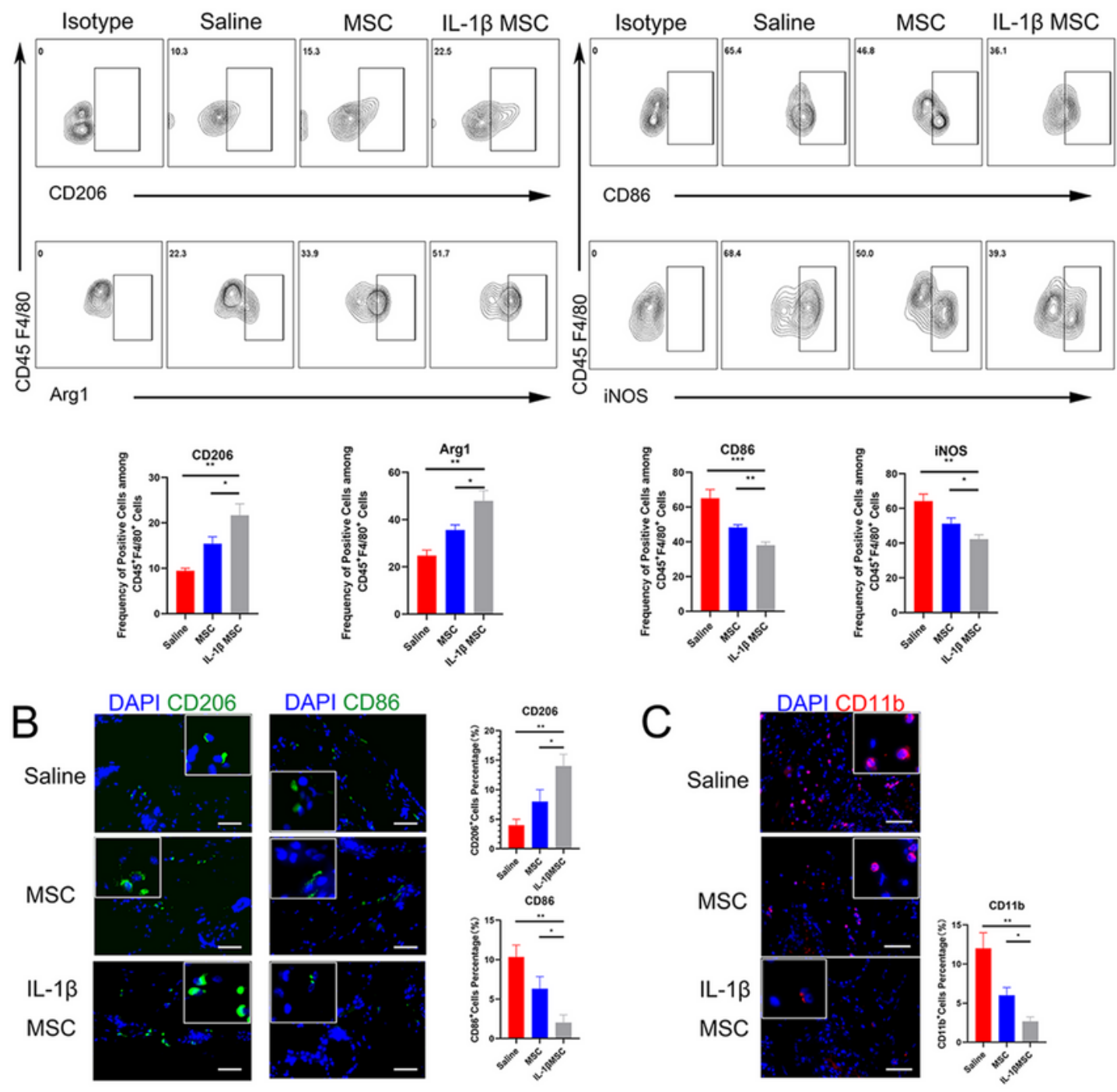

D

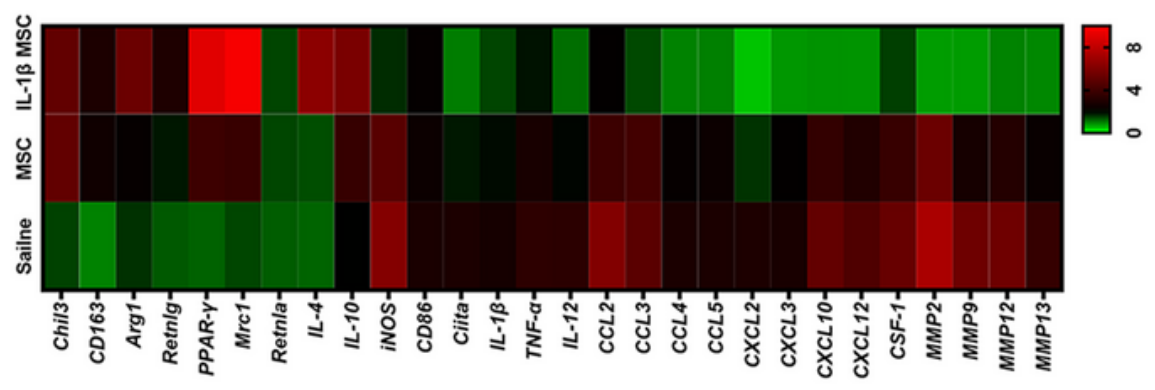

Anti-inflammmatory genes

Pro-inflammmatory genes

\section{Figure 5}

Macrophages changed from a proinflammatory phenotype to an anti-inflammatory phenotype in the prostate. A. Proportion of CD206 and Arg1 in CD45+F4/80+ macrophages in the prostates of the saline, MSC and IL-1 $\beta$-primed MSC groups by flow cytometry. Proportion of CD86 and iNOS in CD45+F4/80+ macrophages in the prostates of the saline, MSC and IL-1 $\beta$-primed MSC groups determined by flow cytometry ( $n=6$ per group). B. Proportion of CD206+ cells and CD86+ cells in the prostates of the saline, 
MSC and IL-1 $\beta$-primed MSC groups by IF $(n=6$ per group, bar $=50 \mu \mathrm{m})$. C. Proportion of CD11 $\mathrm{b}+\mathrm{cells}$ in the MSC and IL-1 $\beta$-primed MSC groups by IF $(n=6$ per group, bar $=50 \mu \mathrm{m})$. D. The expression of antiinflammatory genes in in situ macrophages in the saline, MSC and IL-1 $\beta$-primed MSC groups, as determined by RT-qPCR; the expression of proinflammatory genes in in-situ macrophages in the saline, MSC and IL-1 $\beta$-primed MSC groups, as determined by RT-qPCR ( $n=6$ per group). Error bars indicate SD. $\star p<0.05, * \star p<0.01, * \star * p<0.001$.

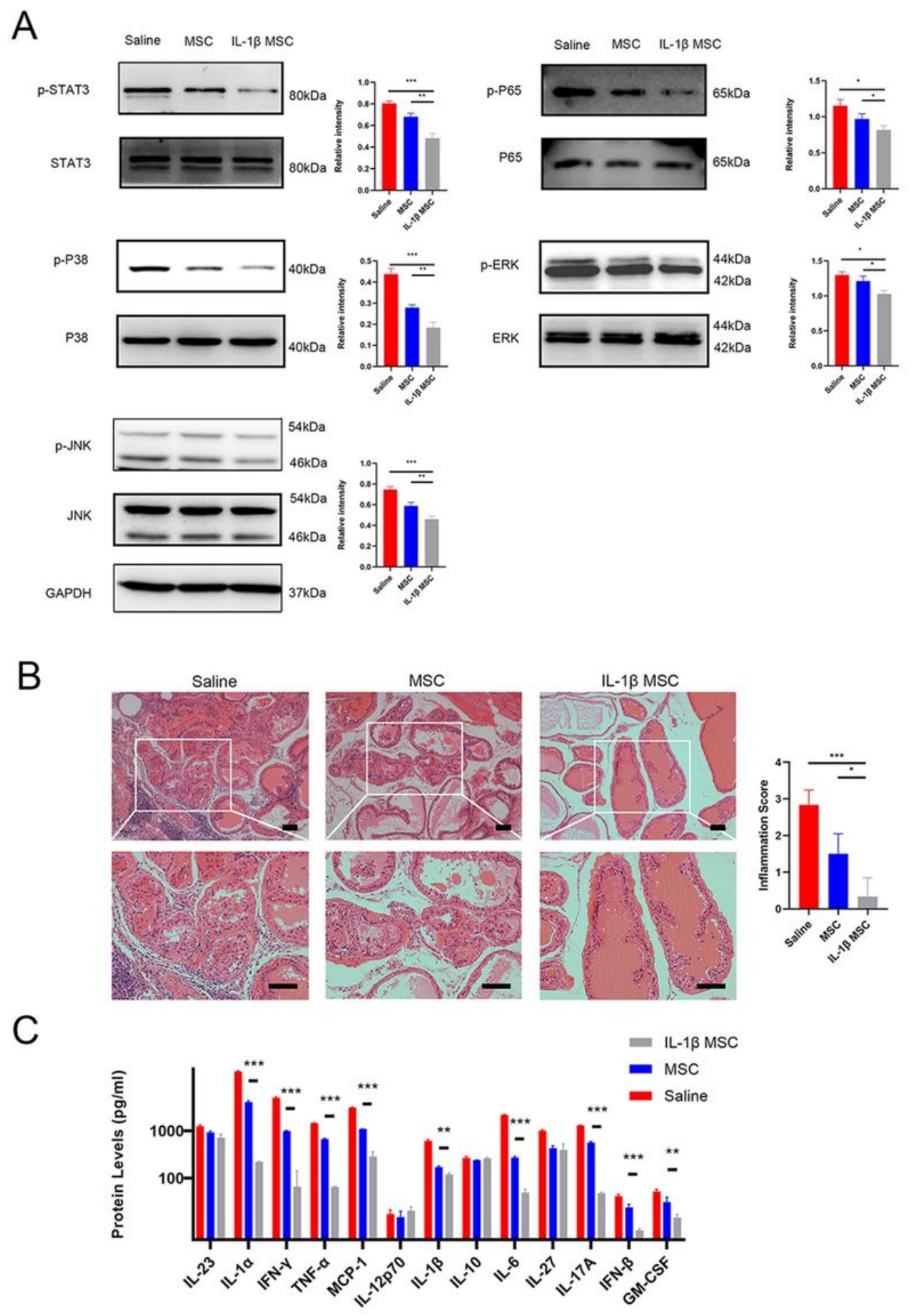

Figure 6 
Expression of inflammation-related pathways decreased after treatment, and inflammation in the prostate was reduced. A. Western blotting was used to detect the phosphorylation of P65, STAT3, JNK, ERK and P38 in the prostates of the saline, MSC, and IL-1 $\beta$-primed MSC groups after treatment $(n=6$ per group). B. The inflammation score and HE-stained slices of prostate tissue indicated the inflammation level after MSC infusion ( $n=6$ per group). C. Inflammatory factors in the prostates of the saline, MSC, and IL-1 $\beta$-primed MSC groups by BiolegendplexTM bead-based immunoassays ( $n=6$ per group). Error bars indicate SD. ${ }^{*} p<0.05,{ }^{*} p<0.01,{ }^{* *} p<0.001$.
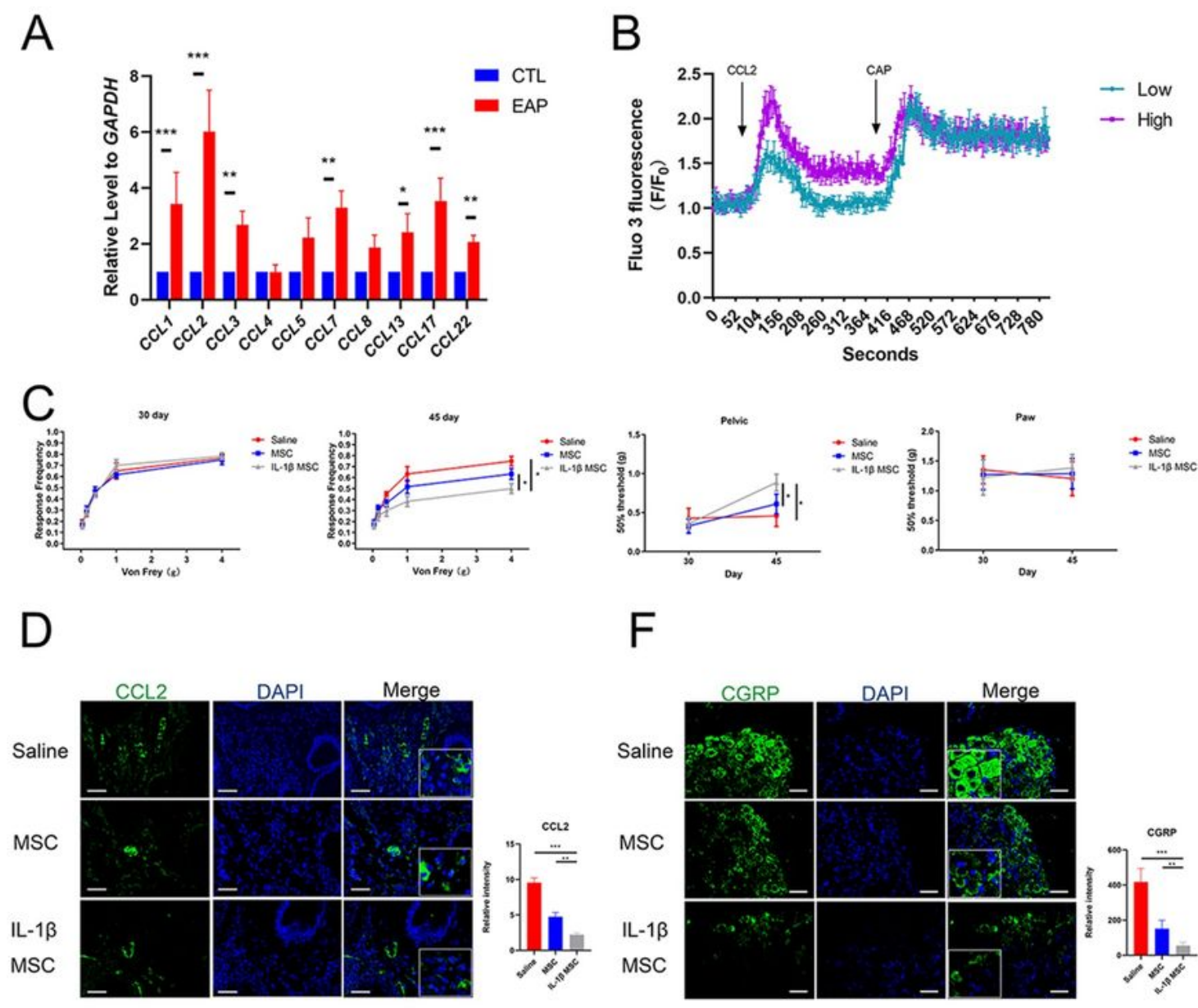

$\mathrm{F}$
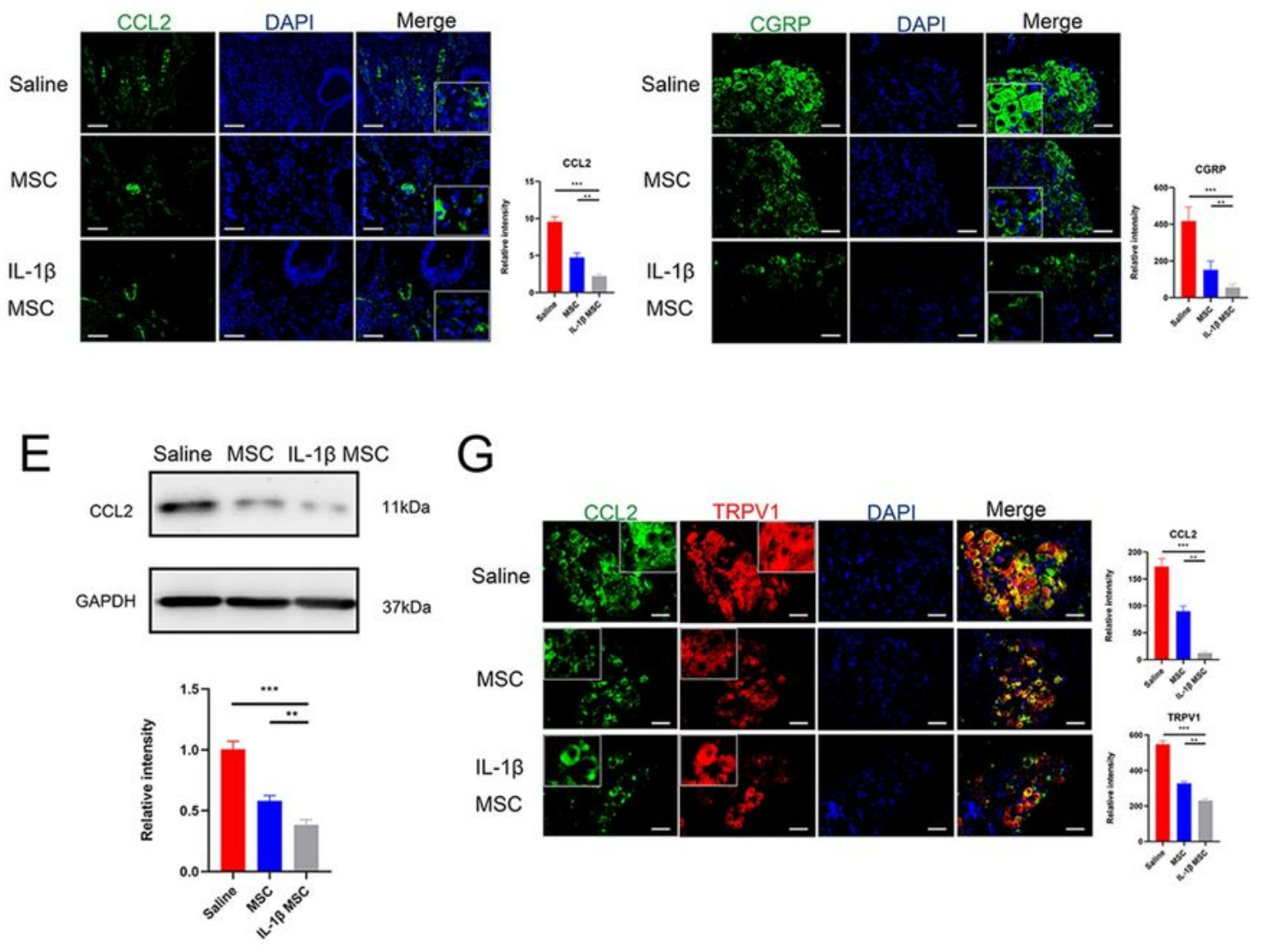


\section{Figure 7}

$\mathrm{CP} / \mathrm{CPPS}$ pain symptoms were relieved after treatment. A. Expression of CCL2 mRNA in EAP mice and control group mice. B. Ca2+ influx in DRGs following treatment with different concentrations of CCL2. Low: $100 \mathrm{ng} / \mathrm{mL}$; high: $300 \mathrm{ng} / \mathrm{ml}$ ( $\mathrm{n}=3$ per group). CAP, capsaicin (300 nM). C. At 30 days, the pelvic pain response of mice in the saline, MSC and IL-1 $\beta$-primed MSC groups; at 45 days, the pelvic pain response of mice in the saline, MSC and IL-1 $\beta$-primed MSC groups; at 30 and 45 days, the paw pain of mice in the saline, MSC and IL-1 $\beta$-primed MSC groups ( $n=6$ per group). D. Expression of CCL2 in the prostates of the saline, MSC and IL-1 $\beta$-primed MSC groups by IF $(n=6$ per group, bar $=50 \mu \mathrm{m})$. E. Expression of CCL2 in the prostates of the saline, MSC and IL-1 $\beta$-primed MSC groups by Western blotting ( $n=6$ per group). F. Expression of CGRP in the saline, MSC and IL-1 $\beta$-primed MSC groups by IF $(n=6$ per group, bar $=50 \mu \mathrm{m})$. G. Expression of CCL2 and TRPV1 in the DRGs of the saline, MSC and IL-1 $\beta$-primed MSC groups by IF $(n=6$ per group, bar $=50 \mu \mathrm{m})$. Error bars indicate SD. ${ }^{*} p<0.05,{ }^{\star \star} p<0.01, \star \star \star p<$ 0.001 .

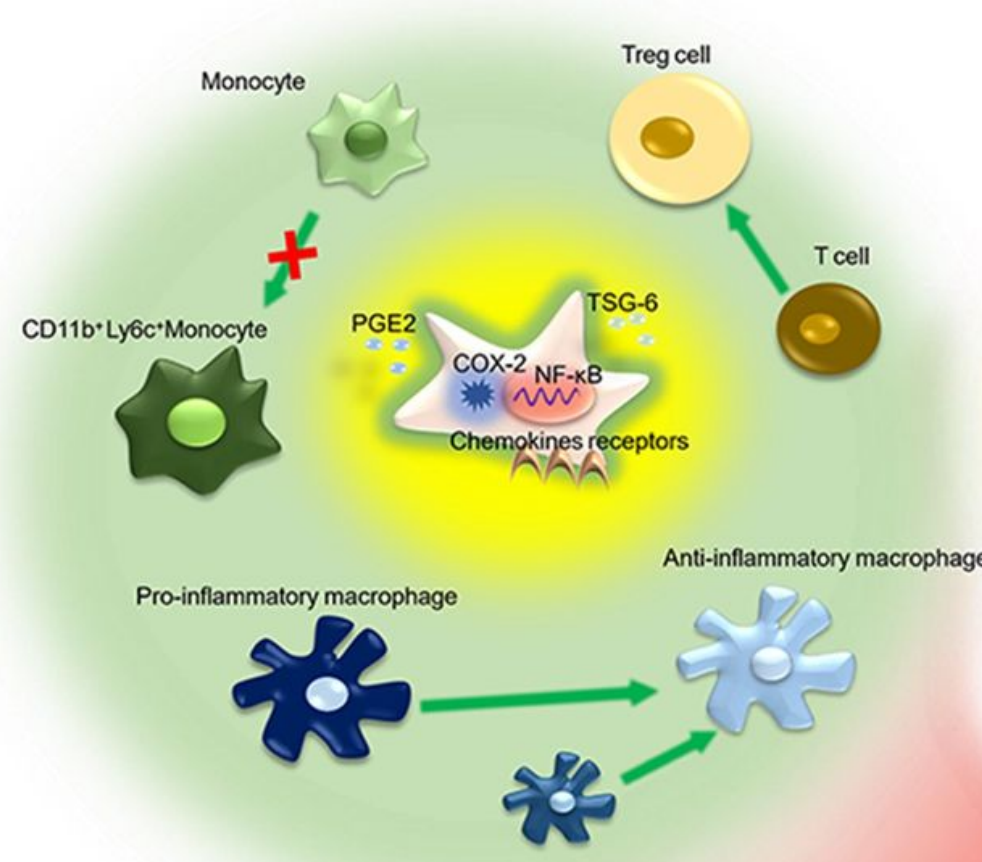

Activated MSC and immune cells in systemic immunity

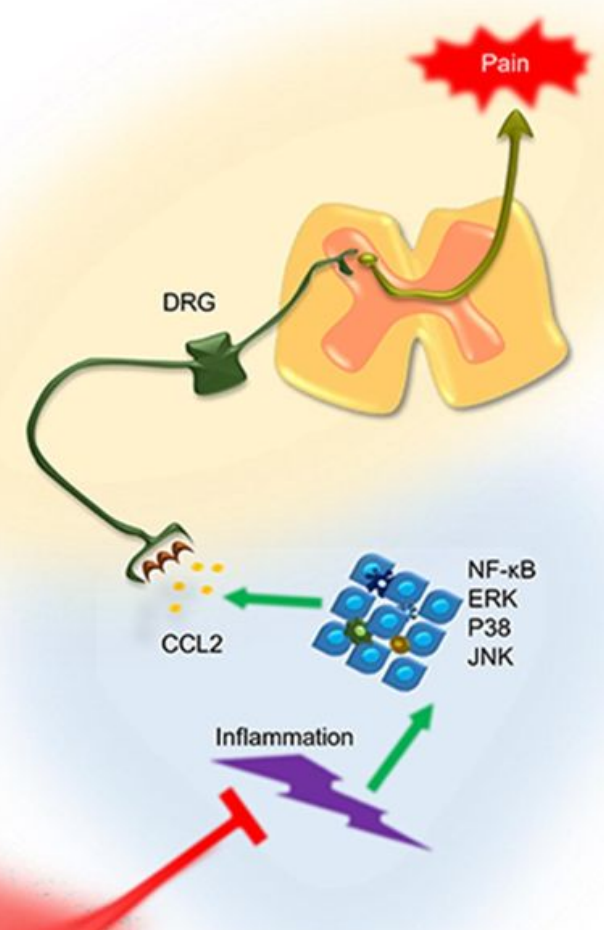

CP/CPPS micro environment

\section{Figure 8}

Schematic of IL-1 $\beta$-primed MSCs in the modulation of macrophages, monocytes, Treg cells, systemic inflammatory response, prostate inflammation, and pelvic pain in CP/CPPS mice. In systemic immunity, IL-1 $\beta$-primed MSCs regulated the inflammatory properties of macrophages from M1 to M2, CD11b+Ly6Chigh monocyte less infiltration and Treg cell accumulation. The above immune cells enhanced inflammatory resolution, inhibited NF-KB, STAT3 and JNK activation of inflammatory sites and inhibited the release of CCL2 in the prostate via systemic immunity. 


\section{Supplementary Files}

This is a list of supplementary files associated with this preprint. Click to download.

- Supplementalfigures.docx

- Supplementaltables.docx 